\title{
Ecosistemas coralinos del Área de Conservación Osa, Costa Rica: estructura y necesidades de conservación
}

\author{
Juan José Alvarado ${ }^{1,2,3}$, Andrés Beita-Jiménez², Sebastián Mena ${ }^{2}$, Cindy Fernández-García ${ }^{1,2,4}$ \& \\ Ana Gloria Guzmán-Mora ${ }^{5}$ \\ 1. Centro de Investigación en Ciencias del Mar y Limnología, Universidad de Costa Rica, San Pedro, 11501-2060 San \\ José, Costa Rica; juanalva76@yahoo.com, cindyfdez@yahoo.com \\ 2. Escuela de Biología, Universidad de Costa Rica; abeitaj@gmail.com, sebasmenago@gmail.com \\ 3. Museo de Zoología, Universidad de Costa Rica. \\ 4. Herbario de la Universidad de Costa Rica. \\ 5. Conservación Internacional; aguzman@conservation.org
}

Recibido 11-VIII-2014. Corregido 20-XI-2014. Aceptado 22-XII-2014.

\begin{abstract}
Osa Conservation Area (Costa Rica) coral ecosystems: structure and conservation needs. Costa Rica is considered one of the 20 most biodiverse countries in the world, which includes it's well known reefs ecosystems. Specifically, the South Pacific region, the Osa Conservation Area (ACOSA), holds one of the richest reefs of the country. Even though many of these reefs have been studied since the 1980's, most of them had focused mainly on coral cover condition. Therefore, the present research aims to complete and update an evaluation of the main biological components of ACOSA's reefs ecosystems, using a standard methodology. Between 2013 and 2014, five localities were visited: Dominicalito, Marino Ballena National Park, Caño Island Biological Reserve, Osa Peninsula and Golfo Dulce, on which 27 sites were evaluated. Transects at two depths in each site were done to estimate substrate cover, reef rugosity, macroinvertebrates diversity and density, and reef fishes composition and biomass. Results indicate that ACOSA's reef are moderately complex and on most of them the substrate is dominated by turf $(62.7 \%)$ and live coral cover is moderate (16.5\%). Substrate cover was significantly different between localities, which can be attributed to adverse environmental conditions for reef development (e.g. sedimentation, pollution). However, reefs in Golfo Dulce and Caño Island BR showed a significant coral cover recovery since last studied. Of 35 taxa of macroinvertebrates identified, $58 \%$ had low abundance or were observed occasionally. Golfo Dulce presented the highest diversity and density of macroinvertebrates and significant differences were observed between localities. On this group, this study is providing an information baseline of most sites analyzed. The echinoids Diadema mexicanum and Eucidaris thouarsii were the most abundant and the conch (Lobatus galeatus) was reported for many of the sites. Of the 90 species of reef fishes documented, ten were common and with the highest densities. There were no significant differences in the diversity and richness of the reef fishes between localities, but fishes' biomass and composition of fish community were different between sites. Caño Island's sites were the most diverse of ACOSA, and presented the highest biomass and trophic levels of the region. Golfo Dulce's reef fish composition differs from the other localities. According to the results, ACOSA's reef ecosystems have a high biodiversity. The ecosystems conditions observed indicate that more conservation efforts, sustainable use and effective management of land and marine resources should be implemented. Ecological monitoring will provide the information about trends and the relationship between reef ecosystems state and environmental conditions. Rev. Biol. Trop. 63 (Suppl. 1): 219-259. Epub 2015 April 01.
\end{abstract}

Key words: Coral community, reef, biomass, diversity, abundance, Eastern Tropical Pacific.

Con sólo $51100 \mathrm{~km}^{2}$ de superficie terrestre $(0.03 \%$ de la mundial $)$ y $589000 \mathrm{~km}^{2}$ de área marina $(0.16 \%$ de la mundial), Costa Rica es considerado uno de los 20 países del mundo con mayor biodiversidad (Obando-Acuña, 2002). Su posición geográfica, sus dos costas y su sistema montañoso, que proveen numerosos y variados microclimas, son algunas de las 
razones que explican esta riqueza natural, tanto en especies como en ecosistemas terrestres y marinos (Obando-Acuña, 2002; Wehrtmann \& Cortés, 2009). Específicamente la biodiversidad marina cuenta con más de 6700 especies (Wehrtmann \& Cortés, 2009), de las cuáles un gran porcentaje dependen de los ecosistemas arrecifales para el desarrollo total o parcial de sus ciclos de vida.

Los arrecifes coralinos son uno de los ecosistemas más susceptibles a disturbios, ya que, por su ubicación, se encuentran fuertemente asociados a las actividades humanas que se dan en la costa y en las cuencas que desembocan en sus cercanías (Hutchings, 1986). Sin embargo, al ser ecosistemas con una alta resiliencia, mantienen una alta diversidad, y con ello una gran variedad de servicios ambientales como la pesca, turismo, bioprospección, protección de la línea de costa, entre otros (Spurgeon, 1992).

En el Pacífico de Costa Rica, los arrecifes y comunidades coralinas se consideran como una de las formaciones más importantes del Pacífico Tropical Oriental (PTO) (Cortés, 2003). Varias de las áreas marinas protegidas que se han establecido en esta costa, poseen como justificación la protección de estos ecosistemas, hecho que ha permitido su incorporación como elementos claves de conservación en los esquemas de protección del país (Alvarado, Herrera, Corrales, Asch \& Paaby, 2011a).

Sin embargo, en su mayoría, estas áreas protegidas no poseen una evaluación actualizada del estado de los ecosistemas marinos que albergan, e inclusive varias de ellas no poseen una línea base que detalle la composición y diversidad de estos sistemas. La ausencia de esta línea base y del monitoreo de la condición de salud en que se encuentran estos recursos hace que sea difícil cuantificar el estado de conservación de estos ecosistemas, y consecuentemente de los servicios que estos brindan. Asimismo, la ausencia de análisis de las tendencias de cambio temporales impide determinar la efectividad de las acciones de manejo y protección que se realizan dentro de las áreas protegidas. Además, el país se enfrenta a una pérdida paulatina de diversidad, por efectos de cambio climático, acidificación de los océanos y modificación de la línea de costa al encontrarse dentro de las zonas de mayor riesgo ante este fenómeno (Giorgi, 2006; Neelin, Münnich, $\mathrm{Su}$, Meyerson, \& Holloway, 2006; Manzello, 2010a, b). Esto hace evidente la necesidad de contar con un sistema de conservación efectivo, que incluya y conserve realmente la riqueza que posee. Así como, de un sistema de monitoreo que permita evaluar el estado de salud de la biodiversidad y detecte las posibles amenazas.

En la costa Pacífica de Costa Rica, se ha desarrollado la evaluación periódica de arrecifes en zonas específicas no protegidas del Pacífico Norte, como Bahía Salinas y Bahía Culebra, y en áreas marinas protegidas (AMP) de las Áreas de Conservación Guanacaste, Isla del Coco y Osa (Cortés, Jiménez, Fonseca \& Alvarado, 2010). En términos generales, estas investigaciones han mostrado que una de las zonas con los arrecifes mejor desarrollados está en el Área de Conservación Osa (desde el Río Barú hasta Punta Burica), específicamente en el Parque Nacional Marino Ballena, la Reserva Biológica Isla del Caño y Golfo Dulce (Cortés, 1992; Cortés \& Jiménez, 2003; Quesada-Alpizar \& Cortés, 2006).

Mientras que la biodiversidad y ecología de los arrecifes coralinos del sur de Costa Rica han sido ampliamente descritos por varios autores (Glynn, Druffel \& Dunbar, 1983; Cortés \& Murillo, 1985; Guzmán, Cortés, Richmond \& Glynn, 1987; Guzmán \& Cortés, 1989, 2001; Cortés \& Jiménez, 1996; Cortés \& Guzmán, 1998; Jiménez \& Cortés, 2001, 2003; Alvarado, Cortés, Fernández \& Nivia, 2005; Fonseca, Dean \& Cortés, 2006; Alvarado, Fernández \& Cortés, 2009), todas las acciones de monitoreo realizadas a la fecha se han enfocado en la evaluación de la cobertura viva de los corales constructores de los arrecifes. Esos esfuerzos de monitoreo han dejado de lado la complejidad estructural de estos ecosistemas y así como la composición de la fauna y flora asociada. De forma tal, que en la actualidad no existe una línea base completa, ni una cuantificación actualizada y estándar, de los aspectos clave para determinar la condición de estos 
ecosistemas y que facilite la información para la gestión adecuada de estas áreas.

Por lo tanto, los objetivos del presente estudio buscan: 1) elaborar una línea base, mediante la utilización de una metodología estándar, del estado actual (estructura y composición) de los arrecifes y comunidades coralinos del Área de Conservación Osa (ACOSA); 2) realizar una comparación temporal de estos sistemas siempre y cuando exista información confiable de investigaciones previas; y 3 ) determinar tendencias de cambio en el estado de conservación de los recursos marinos que permitan identificar recomendaciones para su manejo.

\section{MATERIALES Y MÉTODOS}

Sitio de estudio: El Área de Conservación Osa, perteneciente al Sistema Nacional de Áreas de Conservación (SINAC) del Ministerio del Ambiente y Energía (MINAE), se encuentra en el Pacífico Sur de Costa Rica, y está integrada por los cantones de Osa, Corredores y Golfito, provincia de Puntarenas. El área tiene una extensión de $4304.8 \mathrm{~km}^{2}$ y $245 \mathrm{~km}$ de línea de costa. El 34\% del área se encuentra bajo alguna categoría de manejo (Quesada-Alpízar \& Cortés, 2006): tres Parques Nacionales (PN), una Reserva Biológica (RB), diez Refugios Nacionales de Vida Silvestre (RNVS), una Reserva Forestal (RF) y dos Humedales Nacionales (HN) (Quesada-Alpízar \& Cortés, 2006). Dentro de estas se protegen $221 \mathrm{~km}^{2}$ de costa, dentro de seis áreas marinas protegidas (AMPs): PN Marino Ballena (PNMB), HN Térraba-Sierpe (HNTS), RB Isla del Caño (RBIC), PN Corcovado (PNC), RNVS Río Oro (RNVSRO) y el PN Piedras Blancas (PNPB) (Alvarado, Cortés, Esquivel \& Salas, 2012). Por su parte, el Golfo Dulce, con un área de $773.97 \mathrm{~km}^{2}$ fue declarado, en junio del 2010, como Área Marina de Pesca Responsable (AMPR), la cual es una herramienta de gestión pesquera instaurada por el Instituto Costarricense de Pesca y Acuicultura (INCOPESCA) (Salas, Ross-Salazar \& Arias, 2012). Una descripción detalla de las condiciones oceanográficas, geológicas y biológicas de ACOSA se puede encontrar en Quesada-Alpízar y Cortés (2006).

Metodología de campo: Dentro de ACOSA, se definieron cinco localidades para realizar la evaluación: Dominicalito, Parque Nacional Marino Ballena (PNMB), Reserva Biológica Isla del Caño (RBIC), Península de Osa y Golfo Dulce, debido a que son zonas que presentan arrecifes y comunidades coralinas (Cuadro 1). En cada una de estas se escogieron sitios considerados representativos de los ecosistemas arrecifales de la localidad. Se realizaron dos visitas, una en febrero del 2013 y la segunda en enero 2014, a 27 sitios dentro de las cinco localidades (Cuadro 1). En cada sitio, se trabajaron dos profundidades (somero: $2-8 \mathrm{~m}$ y profundo $8-16 \mathrm{~m}$ ). En cada profundidad se definieron, mediante una cinta métrica, tres transectos de $10 \mathrm{~m}$ de longitud, paralelos a la costa y separados por $10 \mathrm{~m}$ entre ellos. En cada transecto se cuantificó: 1) cobertura de fondo y rugosidad del arrecife, 2) la diversidad y densidad de macroinvertebrados y 3) la diversidad y biomasa de peces arrecifales.

Cobertura del fondo y rugosidad: En cada uno de los transectos, se colocó, a cada metro, una cuadrícula de $1 \mathrm{~m}^{2}$, subdividida en cuadrantes de $0.01 \mathrm{~m}^{2}$, con el objetivo de analizar la cobertura del fondo (Weinberg, 1981). La cobertura se cuantificó en los $10 \mathrm{~m}$ consecutivos a lo largo de cada transecto, siguiendo la cinta métrica sin dejar espacios entre ellas: se analizaron tres transectos $(10 \mathrm{~m}$ largo x $1 \mathrm{~m}$ ancho) en cada profundidad. Se cuantificaron las siguientes categorías para describir la cobertura del sustrato: coral vivo (a nivel de especie), coral muerto, coral blanqueado, macroalgas (a nivel de género), tapete algal o “turf”, algas calcáreas costrosas, algas costrosas, esponja, anémonas, arena, cascajo y otros organismos (e.g. briozoarios, hidrozoos, zoántidos, cirripedios, tunicados, cianobacterias).

La complejidad arrecifal se analizó mediante la medición del índice de rugosidad (IR) del sustrato, variable muy relacionada con la diversidad, abundancia y estado de salud 
CUADRO 1

Sitios de muestreo de los ecosistemas arrecifales en el Área de Conservación Osa.

PN: Parque Nacional; RB: Reserva Biológica; AMP: Área Marina Protegida

TABLE 1

Sampled sites with presence of reef ecosystems at Osa Conservation Area. PN: National Park; RB: Biological Reserve; AMP: Marine Protected Area

\begin{tabular}{|c|c|c|c|c|c|}
\hline \# & Sitio & Localidad & Coordenadas & \# transectos & Protección \\
\hline 1 & El Arbolito & Dominicalito & $9^{\circ} 13^{\prime} 31.80^{\prime \prime} \mathrm{N}-83^{\circ} 50^{\prime} 47.30^{\prime \prime} \mathrm{O}$ & 6 & No AMP \\
\hline 2 & E1 Arbolito \#2 & Dominicalito & $9^{\circ} 13^{\prime} 22.6^{\prime \prime} \mathrm{N}-83^{\circ} 50^{\prime} 45.8^{\prime \prime} \mathrm{O}$ & 3 & No AMP \\
\hline 3 & Cambutal & Dominicalito & $9^{\circ} 12^{\prime} 26.20^{\prime \prime} \mathrm{N}-83^{\circ} 49^{\prime} 45.10^{\prime \prime} \mathrm{O}$ & 3 & No AMP \\
\hline 4 & Bajo Mauren & PN Marino Ballena & $9^{\circ} 6^{\prime} 45.30^{\prime \prime} \mathrm{N}-83^{\circ} 44^{\prime} 27.30^{\prime \prime} \mathrm{O}$ & 12 & AMP \\
\hline 5 & Bajo Tres Hermanas & PN Marino Ballena & $9^{\circ} 6^{\prime} 25.20^{\prime \prime} \mathrm{N}-83^{\circ} 42^{\prime} 43.30^{\prime \prime} \mathrm{O}$ & 11 & AMP \\
\hline 6 & Isla Ballena & PN Marino Ballena & $9^{\circ} 6^{\prime} 23.80^{\prime \prime} \mathrm{N}-83^{\circ} 43^{\prime} 34.20^{\prime \prime} \mathrm{O}$ & 12 & AMP \\
\hline 7 & Isla Ballena NE & PN Marino Ballena & $9^{\circ} 06^{\prime} 14.6^{\prime \prime} \mathrm{N}-83^{\circ} 43^{\prime} 18.6^{\prime \prime} \mathrm{O}$ & 3 & AMP \\
\hline 8 & La Viuda & PN Marino Ballena & $9^{\circ} 9^{\prime} 0.90^{\prime \prime} \mathrm{N}-83^{\circ} 46^{\prime} 56.20^{\prime \prime} \mathrm{O}$ & 12 & AMP \\
\hline 9 & Tómbolo NE \#1 & PN Marino Ballena & $9^{\circ} 8^{\prime} 32.20^{\prime \prime} \mathrm{N}-83^{\circ} 45^{\prime} 24.30^{\prime \prime} \mathrm{O}$ & 6 & AMP \\
\hline 10 & Tómbolo NE\#2 & PN Marino Ballena & $9^{\circ} 8^{\prime} 41.30^{\prime \prime} \mathrm{N}-83^{\circ} 45^{\prime} 29.50^{\prime \prime} \mathrm{O}$ & 6 & AMP \\
\hline 11 & Tómbolo sur & PN Marino Ballena & $9^{\circ} 8^{\prime} 49.10^{\prime} \mathrm{N}-83^{\circ} 46^{\prime} 2.30^{\prime \prime O}$ & 6 & AMP \\
\hline 12 & Tres Hermanas & PN Marino Ballena & $9^{\circ} 6^{\prime} 14.70^{\prime \prime} \mathrm{N}-83^{\circ} 42^{\prime} 24.70^{\prime \prime} \mathrm{O}$ & 12 & AMP \\
\hline 13 & Cueva del Tiburón & RB Isla del Caño & $8^{\circ} 42^{\prime} 45.70^{\prime \prime} \mathrm{N}-83^{\circ} 53^{\prime} 23.20^{\prime \prime} \mathrm{O}$ & 12 & AMP \\
\hline 14 & El Jardín & RB Isla del Caño & $8^{\circ} 42^{\prime} 55.70^{\prime \prime} \mathrm{N}-83^{\circ} 52^{\prime} 28.30^{\prime \prime} \mathrm{O}$ & 12 & AMP \\
\hline 15 & Isla del Caño Sur & RB Isla del Caño & $8^{\circ} 41^{\prime} 53.90^{\prime \prime} \mathrm{N}-83^{\circ} 53 ’ 20.70^{\prime \prime} \mathrm{O}$ & 6 & AMP \\
\hline 16 & La Catarata & RB Isla del Caño & $8^{\circ} 42^{\prime} 24.00^{\prime \prime} \mathrm{N}-83^{\circ} 51^{\prime} 58.90^{\prime \prime} \mathrm{O}$ & 12 & AMP \\
\hline 17 & Piedra Llorona & Península de Osa & $8^{\circ} 30^{\prime} 34.8^{\prime \prime} \mathrm{N}-83^{\circ} 40^{\prime} 00.1^{\prime \prime} \mathrm{O}$ & 6 & AMP \\
\hline 18 & Roca Campanario & Península de Osa & $8^{\circ} 38^{\prime} 16.70^{\prime \prime} \mathrm{N}-83^{\circ} 44^{\prime} 10.80^{\prime \prime} \mathrm{O}$ & 6 & No AMP \\
\hline 19 & San Josecito & Península de Osa & $8^{\circ} 40^{\prime} 15.58^{\prime \prime} \mathrm{N}-83^{\circ} 43^{\prime} 5.44^{\prime \prime} \mathrm{O}$ & 12 & No AMP \\
\hline 20 & San Pedrillo & Península de Osa & $8^{\circ} 36^{\prime} 48.9^{\prime \prime} \mathrm{N}-83^{\circ} 44^{\prime} 17.5^{\prime \prime} \mathrm{O}$ & 6 & AMP \\
\hline 21 & Islotes & Golfo Dulce & $8^{\circ} 43^{\prime} 49.50^{\prime \prime} \mathrm{N}-83^{\circ} 23^{\prime} 7.70^{\prime \prime} \mathrm{O}$ & 12 & No AMP \\
\hline 22 & Mogos & Golfo Dulce & $8^{\circ} 43^{\prime} 20.50^{\prime \prime} \mathrm{N}-83^{\circ} 24^{\prime} 36.40^{\prime \prime} \mathrm{O}$ & 12 & No AMP \\
\hline 23 & Nicuesa & Golfo Dulce & $8^{\circ} 39^{\prime} 25.40^{\prime \prime} \mathrm{N}-83^{\circ} 16^{\prime} 27.80^{\prime \prime} \mathrm{O}$ & 12 & No AMP \\
\hline 24 & Punta Adela & Golfo Dulce & $8^{\circ} 39^{\prime} 18.20^{\prime \prime} \mathrm{N}-83^{\circ} 17^{\prime} 46.00^{\prime \prime} \mathrm{O}$ & 12 & No AMP \\
\hline 25 & Punta Gallardo & Golfo Dulce & $8^{\circ} 38^{\prime} 10.80^{\prime \prime} \mathrm{N}-83^{\circ} 14^{\prime} 46.10^{\prime \prime} \mathrm{O}$ & 9 & No AMP \\
\hline 26 & Sándalo \#1 & Golfo Dulce & $8^{\circ} 34^{\prime} 43.90^{\prime \prime} \mathrm{N}-83^{\circ} 21^{\prime} 3.90^{\prime \prime} \mathrm{O}$ & 12 & No AMP \\
\hline 27 & Sándalo \#2 & Golfo Dulce & $8^{\circ} 34^{\prime} 39.60^{\prime \prime} \mathrm{N}-83^{\circ} 20^{\prime} 52.00^{\prime \prime} \mathrm{O}$ & 12 & No AMP \\
\hline
\end{tabular}

de los organismos presentes en los arrecifes (Álvarez-Filip, Côté, Gill, Watkinson \& Dulvy, 2011). Para determinar esta variable, en cada transecto, se extendió una cadena de $10 \mathrm{~m}$ de largo con eslabones de $1 \mathrm{~cm}$, siguiendo el contorno del fondo a lo largo de cada uno de los transectos. Mediante la cinta métrica, se determinó la distancia total en línea recta del punto de inicio del transecto al punto final que alcanzó la cadena (Rogers, Garrison, Grober, Hillis \& Franke, 1994; Aronson \& Precht, 1995; Lee, 2006). El IR se calcula restándole a 1 la razón entre la distancia cubierta por la cadena sobre el fondo y los $10 \mathrm{~m}$ de la cadena. Para este índice valores cercanos a 0 representan arrecifes planos, mientras que valores cercanos a 1 representan arrecifes rugosos o más complejos morfológicamente.

Diversidad y abundancia de macroinvertebrados: Se muestreó $1 \mathrm{~m}$ a ambos lados de cada uno de los transectos establecidos $\left(10 \mathrm{~m} \times 2 \mathrm{~m}=20 \mathrm{~m}^{2}\right)$. El buzo se enfocó en revisar entre grietas y rocas, sin causar alteración del 
sustrato. Los macroinvertebrados contabilizados fueron los animales de más de $2.5 \mathrm{~cm}$ en estado de madurez, y conspicuos en el arrecife. Las categorías fueron: moluscos (opistobranquios y otros gasterópodos, bivalvos, y pulpos), crustáceos (langostas y cangrejos flecha), y equinodermos (pepinos de mar, erizos de mar y estrellas de mar). Todos los organismos se identificaron a nivel de género y especie en la medida de lo posible.

Diversidad y biomasa de peces arrecifales: Para determinar la composición íctica en el arrecife, se contabilizó y se estimó la talla de todos los peces observados de la línea del transecto a $5 \mathrm{~m}$ hacia un lado (ancho) y $5 \mathrm{~m}$ de alto ( $10 \mathrm{~m} \times 5 \mathrm{mx} 5 \mathrm{~m})$, formando un túnel imaginario. Se estimó el tamaño de cada pez y se clasificaron en las siguientes categorías de: $<5 \mathrm{~cm}$, 5-10,10-15, 15-20, 20-25, 25-50, 50-100, $100-150,150-200,200-250,250-300 \mathrm{~cm}$. Las frecuencias de tallas de cada especie se transformaron en biomasa usando los parámetros $a$ y $b$ obtenidos de FishBase, donde:

\section{Peso $=a \times$ longitud total ${ }^{b}$}

Las especies se agruparon en categorías de abundancia con base en la densidad y su presencia. De esta manera, se establecieron cuatro categorías: 1) predominantes (la densidad y su presencia son mayores que el promedio), 2) raras (ambos parámetros son menores que el promedio), 3) ocasionales (la densidad supera el promedio pero la presencia está por debajo del mismo) y 4) comunes (presencia y densidad están sobre y bajo el promedio respectivamente). De acuerdo a su nivel trófico, las especies se clasificaron en: depredadores tope, carnívoros, planctívoros y herbívoros (sensu Friedlander \& DeMartini, 2002).

Análisis estadístico: Con el fin de determinar si existen diferencias significativas entre la cobertura de coral vivo, algas calcáreas costrosas, tapetes algales e índice de rugosidad entre los sitios, se realizaron pruebas no paramétricos de ámbitos de Kruskal-Wallis, debido a que ninguna de las variables cumplió con los supuestos del ANOVA (Bakus, 2007). En el caso de que las variables cumplieron con los supuestos del ANOVA, posterior estandarización y transformación $\left(\log _{10}(\mathrm{X}+1)\right)$, se realizó un ANOVA de una vía. A su vez, en el caso de que existiera información de estudios previos de cobertura para alguna de los sitios, se realizaron ANOVAs de una vía, utilizando los promedio, número de transectos (n) y el error o la desviación estándar, dependiendo de lo que se presentará en las publicaciones, previa estandarización y transformación $\left(\log _{10}(\mathrm{X}+1)\right)$ de los datos. Todas estas pruebas estadísticas fueron realizadas en el programa Sigma Stat 3.5.

Para determinar la similitud entre las localidades, en términos de la cobertura del fondo, la densidad de macroinvertebados y la biomasa de peces, se realizó un análisis de agrupamiento jerárquico y un análisis de escalamiento multidimensional no métrico (nMDS) (Clarke \& Gorley, 2006), basados en una matriz de similitud de Bray-Curtis. Los variables fueron estandarizados y transformados por la función raíz cuarta en el caso de los peces y por la función $\log _{10}(\mathrm{X}+1)$ en el caso de la cobertura del fondo y los macroinvertebrados.

Además, para determinar si existe diferencia entre los agrupamientos de localidades y el grado de protección, se realizó un análisis de similitud de una vía (ANOSIM). Se dividieron los sitios en dos categorías: 1) dentro de áreas marinas protegidas (AMPs) y 2) fuera de AMPs. En el caso de las localidades, La Viuda y Piedra Llorona, aunque se encuentran fuera de los PNMB y PNC respectivamente, fueron consideradas dentro de las áreas protegidas. Esto debido a que localmente se cree que estos sitios se ubican dentro del área protección, lo que produce que en ellas se de influencia del área protegida. Con el fin de determinar cuál de las categorías de cobertura de sustrato está influyendo más entre los sitios, se realizó un análisis de componentes principales con la matriz de datos transformada. Con el fin de determinar cuál de las variables está contribuyendo más a la similitud entre las localidades, 
se realizó un de análisis de contribución porcentual de especie (SIMPER).

Para los datos de macroinvertebrados y los peces, se calculó para cada sitio los índices de diversidad de Shannon $\left(\mathrm{H}^{\prime}, \log _{10}\right)$, y la diferenciación taxonómica $\left(\Delta^{*}\right.$; Clarke \& Warwick, 2001). Para éste último índice se utilizaron seis niveles taxonómicos: especie, género, familia, orden, clase, y filo; con sus respectivos valores (pesos) $\omega=16.66$ (especies en el mismo género), 33.33 (misma familia pero géneros diferentes), 50 (mismo orden pero familia diferente), 66.66 (misma clase pero orden diferente), 83.33 (mismo Filo pero clase diferente) y 100 (filos diferentes). Estos dos índices se compararon por localidad para determinar si existían diferencias significativas a través de un ANOVA de una vía. Todos estos análisis se llevaron a cabo utilizando el software PRIMER 6.0 (Clarke \& Gorley 2006).

\section{RESULTADOS}

Cobertura del fondo y rugosidad: En ACOSA, la cobertura del fondo que predominó fue el tapete algal ("turf") con $62.72 \%$, seguido por coral vivo con $16.54 \%$ y arena con $7.05 \%$ (Anexo 1). Las algas calcáreas costrosas (ACC) y las macroalgas presentaron un promedio bajo para el área (4.49\% y $1.71 \%$, respectivamente). La mayor cobertura de turf se observó en la Isla Ballena NE (en PNMB) (89\%), mientras que la menor cobertura se determinó para Nicuesa (en Golfo Dulce) (7.26\%). En relación a la cobertura de coral, ambos sitios mostraron un comportamiento opuesto, donde Nicuesa presentó el valor promedio más alto con $83.43 \%$ y la Isla Ballena NE el más bajo con $0.17 \%$. El sitio Jardín (en RBIC) presentó el valor de cobertura de ACC promedio más alto $(15.70 \%)$, mientras que la Piedra Llorona (en Península de Osa) presentó el valor más alto de macroalgas $(5.33 \%)$. Se observaron diferencias significativas $(\mathrm{p}<0.001)$ en cuanto a la cobertura de ACC, algas costrosas, macroalgas, turf, arena y coral entre los sitios (Cuadro 2).

Los arrecifes de ACOSA son poco complejos topográficamente, con un valor del IR promedio de 0.25. La mayor rugosidad se determinó para Isla del Caño Sur (en RBIC) (0.46), seguida por Las Tres Hermanas (en PNMB) (0.45), La Catarata (en RBIC) (0.42) y los Islotes (en Golfo Dulce) (0.39) (Anexo 1). Estos sitios, con la excepción de Isla del Caño Sur, están compuestos principalmente de arrecifes de colonias masivas grandes de Porites lobata. En los demás 23 sitios de ACOSA, la rugosidad varió entre 0.12 y 0.28 , y en varios de ellos predominaron los corales del género Pocillopora, que son corales ramificados, o fueron fondos de roca basáltica poco compleja. Al comparar entre todos los sitios, se observaron diferencias significativas $\left(\mathrm{F}_{23,216}=7.684\right.$, $\mathrm{p}<0.001)$. Las especies del género Pocillopora fueron las de mayor contribución porcentual (34\%) al total de la cobertura coralina de ACOSA, seguido por corales del género Psammocora con $26.9 \%$, y en tercer lugar el coral P. lobata con $20.1 \%$ (Fig. 1). Otras especies tuvieron una contribución inferior al 6\%.

La composición del fondo evidenció la presencia de dos grupos de sitios $(70 \%$ de similitud) (Fig. 2A, B). El primer grupo conformado por sitios de Golfo Dulce y un sitio en Península de Osa, y un segundo grupo formado por los otros sitios. De acuerdo al ANOSIM utilizando el factor localidad, la composición del fondo no es semejante entre ellas $(R=0.414, p<0.001)$,

\section{CUADRO 2}

Análisis de variancia de una vía en rangos (prueba de Kruskal-Wallis) entre los sitios de muestreo de acuerdo a la categoría de sustrato en el Área de Conservación Osa

TABLE 2

Kruskal-Wallis One Way Analysis of Variance Rank based on substrate factor between sampled sites at Osa Conservation Area

\begin{tabular}{lccc}
\multicolumn{1}{c}{ Categoría } & $\mathrm{H}$ & $\mathrm{g.l.}$ & $\mathrm{p}$ \\
Alga calcárea costrosa & 129.715 & 26 & $<0.001$ \\
Alga costrosa & 60.812 & 26 & $<0.001$ \\
Arena & 97.417 & 26 & $<0.001$ \\
Cascajo & 69.302 & 26 & $<0.001$ \\
Coral & 160.218 & 26 & $<0.001$ \\
Macroalga & 12.958 & 26 & $<0.001$ \\
Turf & 157.153 & 26 & $<0.001$ \\
\hline
\end{tabular}




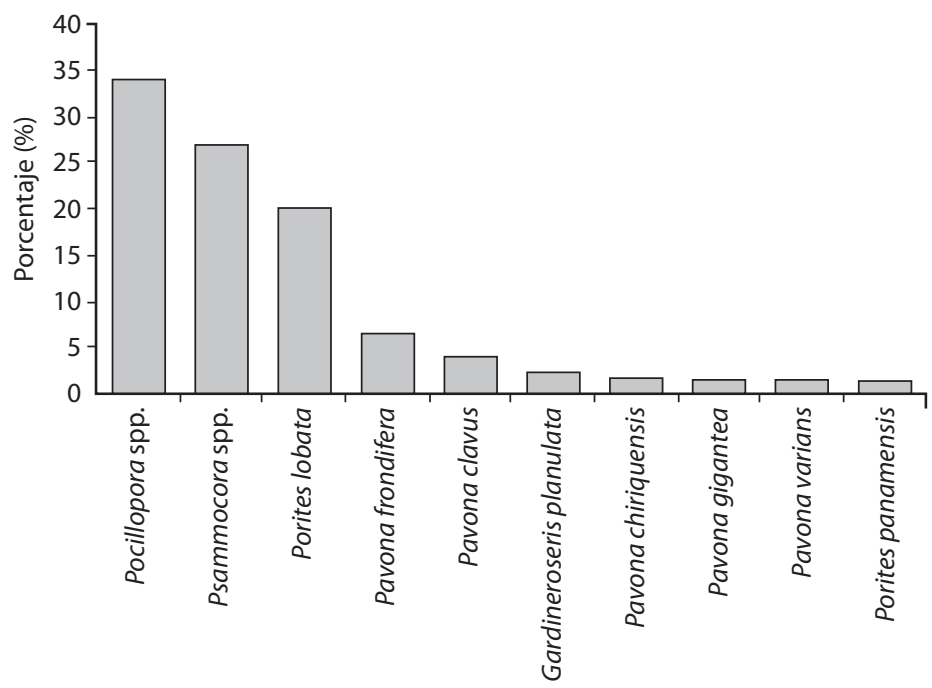

Fig. 1. Contribución porcentual por especie de coral al total de la cobertura coralina en el Área de Conservación Osa. Fig. 1. Coral species percentages from total coral cover at Osa Conservation Area.

siendo Golfo Dulce estadísticamente diferente a las otras cuatro localidades $(\mathrm{p}<0.05)$. Asimismo, las localidades Dominicalito e Isla del Caño mostraron ser estadísticamente diferentes entre sí $(\mathrm{p}<0.05)$. Al analizar los sitios según su ubicación dentro o fuera de AMPs, (Fig. 2C) se observan diferencias significativas en la similitud entre los grupos $(\mathrm{R}=0.289, \mathrm{p}<0.001)$.

De acuerdo al análisis de componentes principales (ACP), hay tres componentes principales (CP) que están explicando el 75.2\% de la variación espacial de los sitios (Fig. 3). El CP1 explica el $40.2 \%$ y está compuesta principalmente por la cobertura de coral vivo y arena. El CP2 explica el $22.5 \%$ y está compuesto principalmente por cascajo y arena, mientras que el CP3 explica el $12.5 \%$ de la variación y está compuesto por la categoría Otro. La influencia de estos CP se comprueba con el SIMPER (Cuadro 3), en donde el porcentaje de disimilitud entre todos los 27 sitios está dado por los sustrato coralino, cascajo y arena. Mientras que la similitud entre los sitios de una misma localidad está dado por el porcentaje de la cobertura de los sustratos: turf y ACC en el caso de Dominicalito, el PNMB y la Península de Osa, y de turf y coral para la RBIC y Golfo Dulce. En estas dos localidades las coberturas de coral rondaron entre $17 \%$ y $80 \%$, y las de ACC entre 1 y $15 \%$ (Anexo 1). En las otras tres localidades estas categorías fueron semejantes en ACC, pero no así de coral que estuvo entre $1 \%$ y $37 \%$.

Diversidad y abundancia de macroinvertebrados: Se observaron 35 taxa de macroinvertebrados en los sitios estudiados (Anexo 2), en su mayoría (58\%) fueron raros u ocasionales, $27 \%$ fueron comunes, mientras que los taxa predominantes representaron un 15\%: Diadema mexicanum, Eucidaris thouarsii, holoturios, Pinctada mazatlaica y Spondylus spp. (Fig. 4).

El sitio con mayor riqueza de especies (S) es Isla Ballena, seguido por Bajo Mauren, La Viuda (los tres en PNMB) y Roca Campanario (en Península de Osa) (Anexo 2). Dentro del PNMB se encontró en promedio $11.89 \pm 4.17$ especies por sitio, en Península de Osa $10.00 \pm 3.16$, en la RBIC $9.75 \pm 1.50$, en Dominicalito $9.33 \pm 3.51$ y dentro del Golfo Dulce $9.29 \pm 2.14$. No se observaron diferencias 


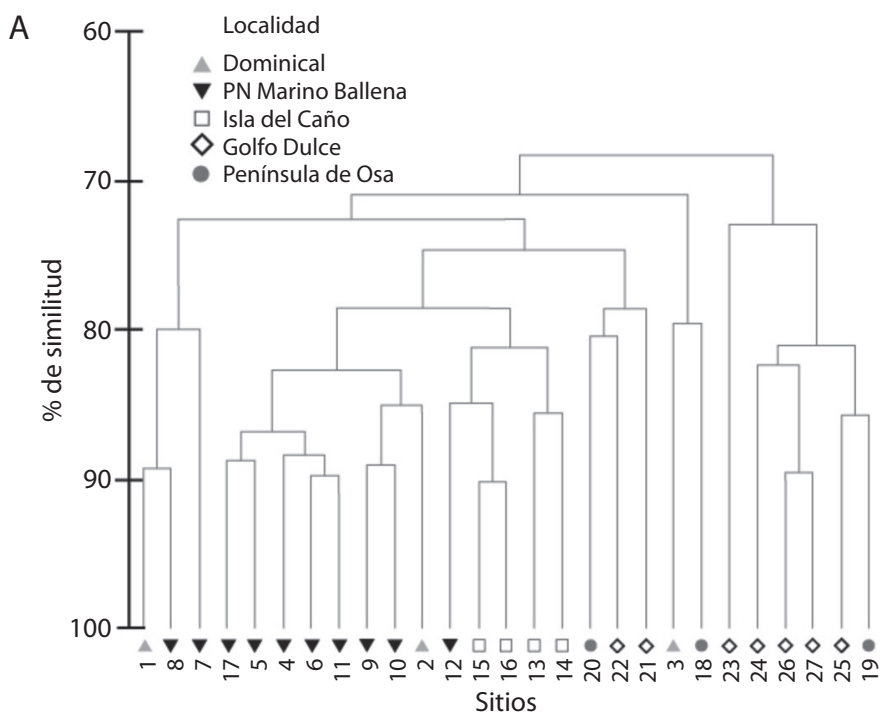

B

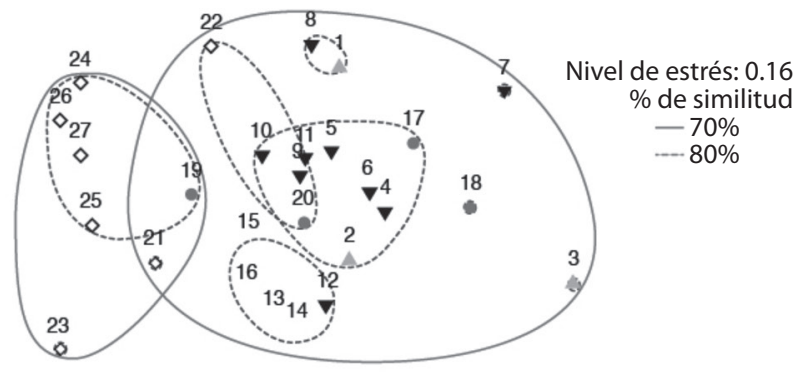

C

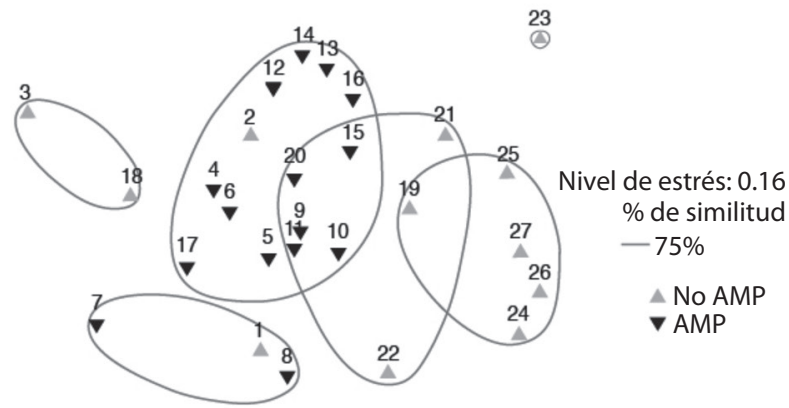

Fig. 2. A) Dendrograma de unión simple, B) análisis multidimensional escalado por factor localidad, C) por factor protección, basados en una matriz de similitud de Bray-Curtis utilizando los porcentajes de cobertura del sustrato en los sitios de muestreo en el Área de Conservación Osa. Número de los sitios se puede observar en el Cuadro 1.

Fig. 2. A) Hierarchical cluster analyses, B) Non metric multi-dimensional scaling analysis by locality factor, and C) by protection factor, based on a Bray Curtis similarity matrix using substrate cover percentages values in the sampled sites at Osa Conservation Area. Sites numbers on Table 1. 

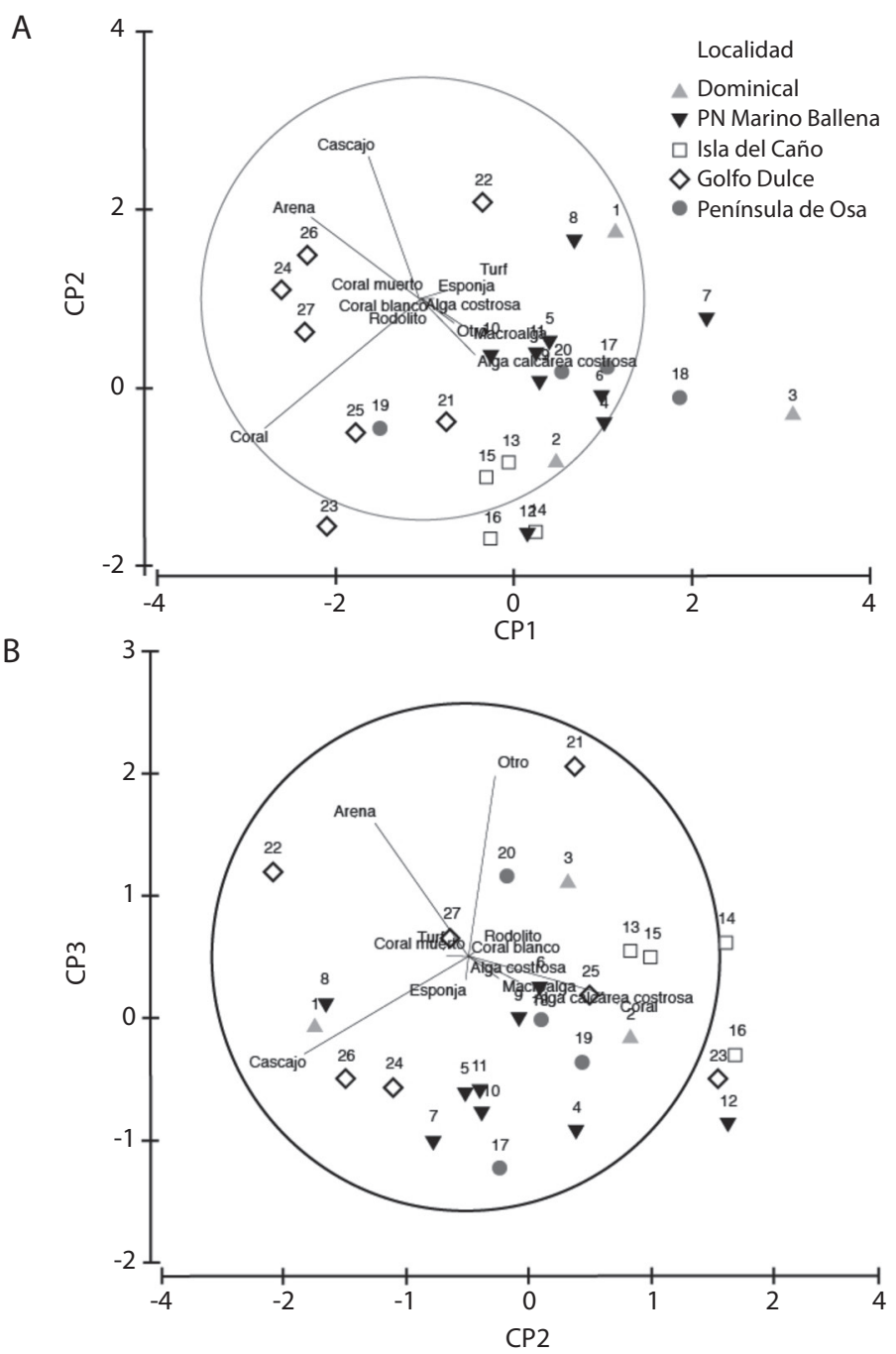

Fig. 3. Análisis de componentes principales (CP) basado en los porcentajes de cobertura del sustrato en los sitios monitoreados en el Área de Conservación Osa, utilizando como factor la localidad. Número de los sitios se puede observar en el Cuadro 1.

Fig. 3. Principal component analysis based on substrate cover percentages values in the sampled sites using locality factor at Osa Conservation Area. Sites numbers on Table 1.

significativas en la riqueza de especies entre las localidades $\left(\mathrm{F}_{4,22}=0.83, \mathrm{p}=0.52\right)$.

El valor más alto del índice de Shannon (H') se encontró en Golfo Dulce $(0.90 \pm 0.11)$, seguido de la RBIC $(0.85 \pm 0.09)$, el PNMB $(0.85 \pm 0.26)$, Península de Osa $(0.82 \pm 0.11)$ y por último Dominicalito $(0.78 \pm 0.24)$, tampoco se observaron diferencias significativas entre estos valores $\left(\mathrm{F}_{4,22}=0.24, \mathrm{p}=0.91\right)$. El índice de diferenciación taxonómica $\left(\Delta^{*}\right)$ presentó un valor promedio de $91.53 \pm 2.37$ para Dominicalito, $91.33 \pm 0.73$ para la RBIC, $89.67 \pm 2.53$ para el PNMB, 88.66 \pm 3.06 para la Península de Osa y $85.57 \pm 5.44$ para el Golfo Dulce, sin diferencias significativas entre las localidades $\left(\mathrm{F}_{4,22}=2.69, \mathrm{p}=0.06\right)$. 
CUADRO 3

Análisis de Similitud porcentual de la categoría de sustrato entre las localidades de muestreo en el Área de Conservación Osa

TABLE 3

Analysis of Similarities of substrate category between sampled localities at Osa Conservation Area

\begin{tabular}{|c|c|c|c|}
\hline Localidad & $\%$ Similitud & Especies & contribución porcentual \\
\hline Dominicalito & $69.87 \%$ & $\begin{array}{l}\text { Turf } \\
\text { Alga calcárea costrosa }\end{array}$ & $\begin{array}{l}56.65 \% \\
18.38 \%\end{array}$ \\
\hline PN Marino Ballena & $80.63 \%$ & $\begin{array}{l}\text { Turf } \\
\text { Alga calcárea costrosa }\end{array}$ & $\begin{array}{l}42.15 \% \\
15.10 \%\end{array}$ \\
\hline RB Isla del Caño & $83.25 \%$ & $\begin{array}{l}\text { Turf } \\
\text { Coral }\end{array}$ & $\begin{array}{l}33.89 \% \\
24.16 \%\end{array}$ \\
\hline Península de Osa & $73.93 \%$ & $\begin{array}{l}\text { Turf } \\
\text { Alga calcárea costrosa }\end{array}$ & $\begin{array}{l}41.80 \% \\
16.49 \%\end{array}$ \\
\hline Golfo Dulce & $75.75 \%$ & $\begin{array}{l}\text { Turf } \\
\text { Coral }\end{array}$ & $\begin{array}{l}29.06 \% \\
25.11 \%\end{array}$ \\
\hline Dominicalito-PN Marino Ballena & $23.85 \%$ & $\begin{array}{l}\text { Coral } \\
\text { Cascajo }\end{array}$ & $\begin{array}{l}23.66 \% \\
19.11 \%\end{array}$ \\
\hline Dominicalito-RB Isla del Caño & 28.26 & $\begin{array}{l}\text { Coral } \\
\text { Otro }\end{array}$ & $\begin{array}{l}30.78 \% \\
13.25 \%\end{array}$ \\
\hline PN Marino Ballena-RB Isla del Caño & 23.25 & $\begin{array}{l}\text { Coral } \\
\text { Cascajo }\end{array}$ & $\begin{array}{l}21.45 \% \\
17.72 \%\end{array}$ \\
\hline Dominicalito-Golfo Dulce & $38.52 \%$ & $\begin{array}{l}\text { Coral } \\
\text { Arena }\end{array}$ & $\begin{array}{l}25.50 \% \\
17.83 \%\end{array}$ \\
\hline PN Marino Ballena-Golfo Dulce & $31.60 \%$ & $\begin{array}{l}\text { Coral } \\
\text { Arena }\end{array}$ & $\begin{array}{l}19.89 \% \\
18.48 \%\end{array}$ \\
\hline RB Isla del Caño-Golfo Dulce & $29.01 \%$ & $\begin{array}{l}\text { Cascajo } \\
\text { Alga Calcárea costrosa }\end{array}$ & $\begin{array}{l}18.81 \% \\
14.86 \%\end{array}$ \\
\hline Dominicalito-Península de Osa & $26.07 \%$ & $\begin{array}{l}\text { Coral } \\
\text { Arena }\end{array}$ & $\begin{array}{l}24.53 \% \\
18.13 \%\end{array}$ \\
\hline PN Marino Ballena-Península de Osa & $21.52 \%$ & $\begin{array}{l}\text { Coral } \\
\text { Arena }\end{array}$ & $\begin{array}{l}20.36 \% \\
20.11 \%\end{array}$ \\
\hline RB Isla del Caño-Península de Osa & $23.95 \%$ & $\begin{array}{l}\text { Coral } \\
\text { Arena }\end{array}$ & $\begin{array}{l}20.90 \% \\
16.79 \%\end{array}$ \\
\hline Golfo Dulce-Península de Osa & $30.45 \%$ & $\begin{array}{l}\text { Coral } \\
\text { Arena }\end{array}$ & $\begin{array}{l}19.08 \% \\
18.61 \%\end{array}$ \\
\hline
\end{tabular}

Al comparar las densidades por especie entre los sitios (Fig. 5 A, B), se observó un patrón de agrupamiento que separa los sitios del Golfo Dulce (con excepción de Nicuesa y Punta Adela) de las otras cuatro localidades, Estos dos sitios de Golfo Dulce, se asemejan más a El Bajo Tres Hermanas (en PNMB) y San Josecito (en Península de Osa). Se observa una segunda agrupación conformada por los sitios en PNMB, Bajo Mauren, Isla Ballena, Isla Ballena NE, Tres Hermanas y Roca Campanario en Península de Osa. Por su parte, la composición de macroinvertebrados de los sitios de la RBIC parece ser particular de la localidad, con excepción del sitio Isla del Caño Sur.

Según el análisis de similitud (ANOSIM), la composición de macroinvertebrados difiere entre localidades $(\mathrm{R}=0.28, \mathrm{p}=0.003)$, sin embargo no se detectó una similitud significativa entre Dominicalito y el PNMB $(\mathrm{R}=-0.05$, $\mathrm{p}=0.6)$, Dominicalito y Península de Osa $(\mathrm{R}=$ $0.06, \mathrm{p}=0.7)$; y el PNMB y la Península de Osa $(\mathrm{R}=-0.1, \mathrm{p}=0.7)$. Lo anterior concuerda con el 


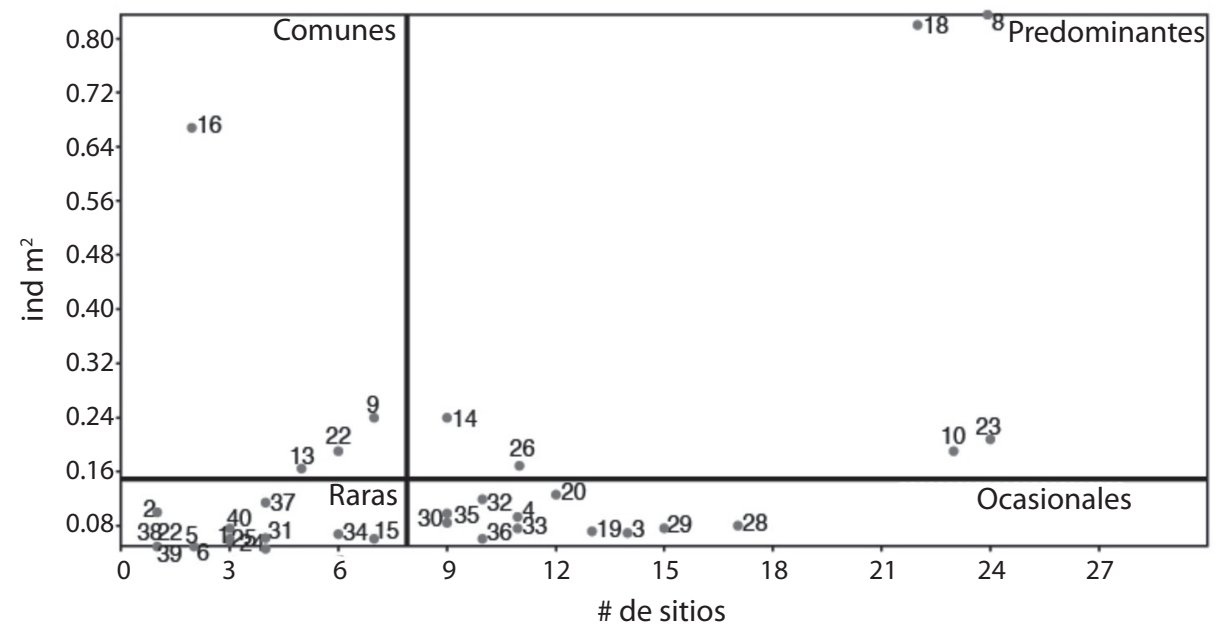

Fig. 4. Categorías de abundancia de macroinvertebrados en ACOSA, basadas en la densidad (ind $\mathrm{m}^{-2}$ ) y la presencia (\# de sitios donde la especie fue observada) de todas las especies. Líneas negras gruesas indican el valor promedio de la densidad y de la ocurrencia. Número de las especies se puede observar en el Anexo 2.

Fig. 4. Macroinvertebrate abundance categories at Osa Conservation Area, based on densities (ind $\mathrm{m}^{-2}$ ) and occurrence (number of sites where the species was observed). Black bold lines show mean values of densities and occurrence. Species numbers on digital appendix 2 .

análisis SIMPER, donde las mismas combinaciones de localidades obtuvieron el menor porcentaje de disimilitud (Cuadro 4). Según este análisis, las especies que más contribuyeron con la similitud entre los sitios dentro de cada localidad y con la disimilitud entre localidades son D. mexicanum, E. thouarsii, P. mazatlanica, Spondylus spp., Murex spp. y Echinometra vanbrunti (Cuadro 4).

Diversidad y biomasa de peces: Se encontraron 90 especies de peces en toda ACOSA, la mayoría (58\%) fueron ocasionales, mientras que un $31 \%$ fueron comunes (Anexo 3, Fig. 6). Diez de estas especies mostraron alta densidad y presencia: Abudefduf troschelii, Chromis atrilobata, Haemulon maculicauda, Halichoeres dispilus, Lutjanus guttatus, Prionurus laticlavius, Scarus ghobban, Stegastes acapulcoensis, Stegastes flavilatus y Thalassoma lucasanum (Anexo 3, Fig. 6).

El Jardín (en RBIC) y El Arbolito \#2 (en Dominicalito) fueron los sitios con mayor y menor riqueza de especies respectivamente
(Anexo 3). El promedio del número de especies por sitio fue mayor en la RBIC (37.50 $\pm 10.53 \mathrm{spp}$. sitio $\left.^{-1}\right)$ y menor en Dominicalito (14.15 \pm 7.09 spp. sitio $\left.^{-1}\right)$, por su parte, las localidades en el PNMB (29.55 \pm 6.95 spp. sitio $\left.{ }^{-1}\right)$, la Península de Osa $\left(26 \pm 5.60\right.$ spp. sitio $\left.{ }^{-1}\right)$ y el Golfo Duce $\left(21.86 \pm 6.39\right.$ spp. sitio $\left.^{-1}\right)$ no difirieron significativamente entre sí $\left(\mathrm{F}_{4,26}=5.41, \mathrm{p}=0.003\right.$; Tukey $\mathrm{p}<0.05$ ). En cuanto a su diversidad, se obtuvo valores mayores en la RBIC y el PNMB con $1.20 \pm 0.12$ y $1.16 \pm 0.10$ respectivamente, en una posición intermedia se encontraron la Península de Osa con $1.01 \pm 0.13$, y el Golfo Dulce con $0.96 \pm 0.16$, mientras que en Dominicalito presentó el menor valor con $0.82 \pm 0.22$ $\left(\mathrm{F}_{4,26}=5.19, \mathrm{p}=0.004\right.$; Tukey $\left.\mathrm{p}<0.05\right)$. La diferenciación taxonómica presentó el mayor valor en el arrecife de Punta Adela (en Golfo Dulce), y un valor mínimo en El Arbolito \#2 (Anexo 3), sin embargo no se observaron diferencias significativas al comparar entre todas las localidades $\left(\mathrm{F}_{4,26}=0.08, \mathrm{p}=0.987\right)$.

La biomasa de las especies de peces variaron significativamente entre las localidades 

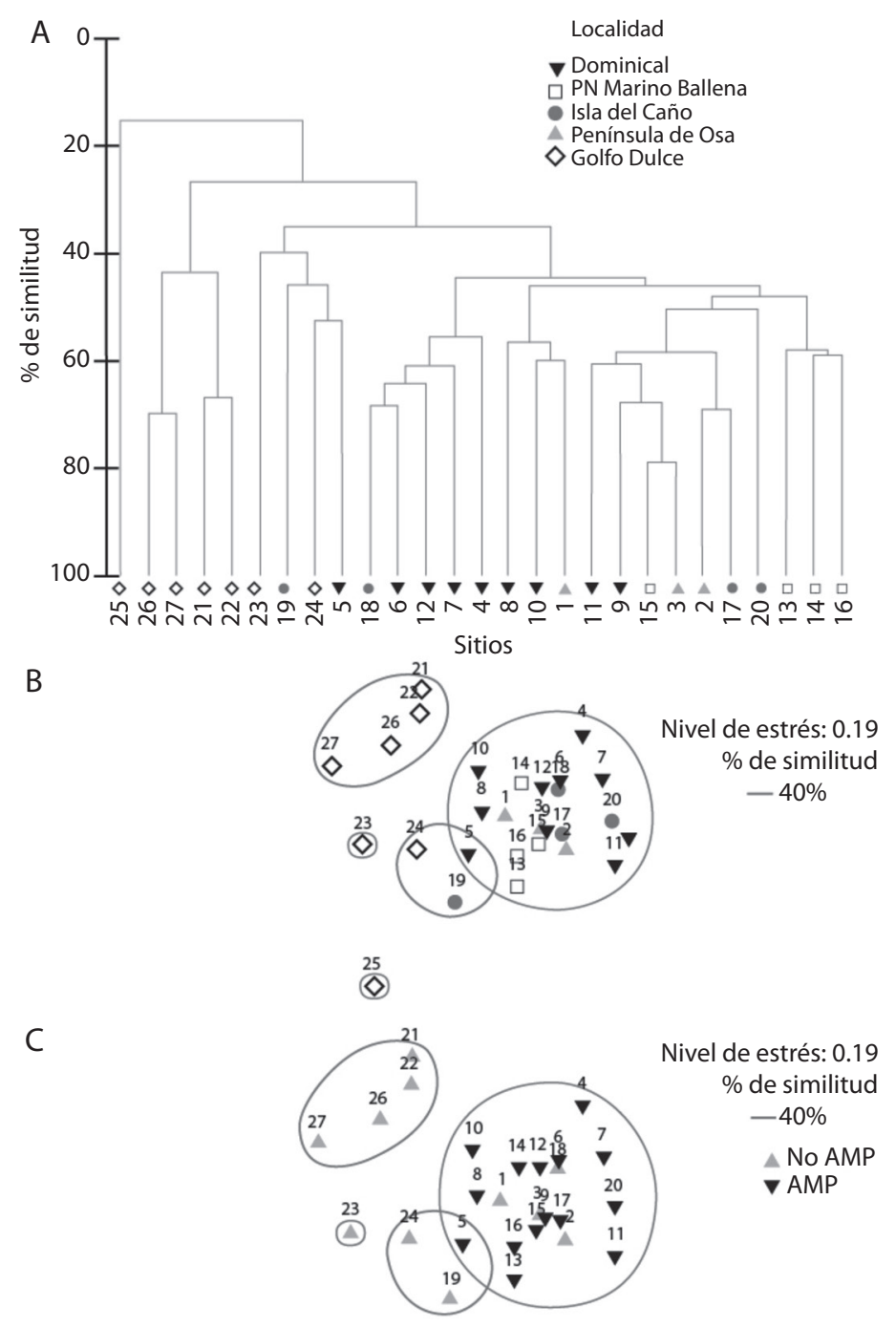

25

Fig. 5. A) Dendrograma de unión simple, B) análisis multidimensional escalado por factor localidad, C) por factor protección, basados en una matriz de similitud de Bray-Curtis utilizando los valores de densidad de macroinvertebrados en los sitios de muestreo en el Área de Conservación Osa. Número de los sitios se puede observar en el Cuadro 1.

Fig. 5. A) Hierarchical cluster analyses, B) Non metric multi-dimensional scaling analysis by locality factor, and C) by protection factor, based on a Bray Curtis similarity matrix using macroinvertebrate densities values in the sampled sites at Osa Conservation Area. Sites numbers on Table 1.

de $\operatorname{ACOSA}\left(\mathrm{F}_{4,1899}=3.11, \mathrm{p}=0.01\right)$ y entre los grupos funcionales $\left(\mathrm{F}_{4,1899}=3.05, \mathrm{p}=0.02\right)$. La mayoría de las localidades fueron dominadas por herbívoros con poca presencia de otros grupos, aunque no hubo relación entre las localidades y el grupo funcional $\left(\mathrm{F}_{4,1899}=1.22, \mathrm{p}=0.26\right)$.
Sin embargo, para la RBIC se observó una tendencia con una mayor biomasa de depredadores tope, seguido por planctívoros y herbívoros (Fig. 7). Los sitios estudiados mostraron una gran dispersión, sin que se observara una tendencia clara (Fig. 8 A y B). Sin embargo, los 
CUADRO 4

Resultados del análisis de similitud porcentual (SIMPER) utilizando densidad de macroivertebrados (ind $\mathrm{m}^{-2}$ ), para el periodo 2013-2014, en el Área de Conservación Osa (ACOSA)

TABLE 4

Macroinvertebrates densities (ind $\mathrm{m}^{-2}$ ) similarity percentages (SIMPER) analysis, in 2013 and 2014, at Osa Conservation Area

\begin{tabular}{|c|c|c|c|}
\hline Localidad & $\%$ Similitud & Especies & Contribución porcentual \\
\hline \multirow[t]{3}{*}{ Dominicalito } & $56.43 \%$ & Diadema mexicanum & $60.79 \%$ \\
\hline & & Eucidaris thouarsii & $11.54 \%$ \\
\hline & & Pinctada mazatlanica & $10.98 \%$ \\
\hline \multirow[t]{2}{*}{ P.N. Marino Ballena } & $46.22 \%$ & Diadema mexicanum & $47.3 \%$ \\
\hline & & Pinctada mazatlanica & $11.68 \%$ \\
\hline \multirow[t]{2}{*}{ R. B. Isla del Caño } & $56.41 \%$ & Diadema mexicanum & $49.68 \%$ \\
\hline & & Eucidaris thouarsii & $19.60 \%$ \\
\hline \multirow[t]{3}{*}{ Península de Osa } & $41.70 \%$ & Diadema mexicanum & $52.11 \%$ \\
\hline & & Pinctada mazatlanica & $13.23 \%$ \\
\hline & & Murex sp. & $10.06 \%$ \\
\hline \multirow[t]{3}{*}{ Golfo Dulce } & $33.28 \%$ & Spondylus sp. & $19.08 \%$ \\
\hline & & Pinctada mazatlanica & $17.78 \%$ \\
\hline & & Eucidaris thouarsii & $12.00 \%$ \\
\hline \multirow[t]{2}{*}{ Dominicalito-P.N. Marino Ballena } & $51.86 \%$ & Diadema mexicanum & $21.56 \%$ \\
\hline & & Pinctada mazatlanica & $10.72 \%$ \\
\hline Dominicalito-R.B. Isla del Caño & $45.94 \%$ & Pinctada mazatlanica & $14.02 \%$ \\
\hline P. N. Marino Ballena-Isla del Caño & $56.46 \%$ & Diadema mexicanum & $20.51 \%$ \\
\hline \multirow[t]{3}{*}{ Dominicalito-Península de Osa } & $51.53 \%$ & Diadema mexicanum & $18.54 \%$ \\
\hline & & Pinctada mazatlanica & $13.47 \%$ \\
\hline & & Echinometra vanbrunti & $10.00 \%$ \\
\hline P. N. Marino Ballena-Península de Osa & $53.16 \%$ & Diadema mexicanum & $23.96 \%$ \\
\hline R. B. Isla del Caño-Península de Osa & $56.32 \%$ & Diadema mexicanum & $17.87 \%$ \\
\hline \multirow[t]{2}{*}{ Dominicalito-Golfo Dulce } & $72.85 \%$ & Diadema mexicanum & $25.59 \%$ \\
\hline & & Pinctada mazatlanica & $10.43 \%$ \\
\hline P. N. Marino Ballena-Golfo Dulce & $73.88 \%$ & Diadema mexicanum & $28.77 \%$ \\
\hline Isla del Caño-Golfo Dulce & $71.70 \%$ & Diadema mexicanum & $21.94 \%$ \\
\hline Península de Osa-Golfo Dulce & $75.19 \%$ & Diadema mexicanum & $25.42 \%$ \\
\hline
\end{tabular}

sitios en Golfo Dulce están separados del resto, así como el sitio El Arbolito \#2.

La composición de la comunidad de peces difirió significativamente entre sitios (ANOSIM, $\mathrm{R}=0.466, \mathrm{p}=0.001$ ). Sin embargo las diferencias no fueron perceptibles entre Dominicalito y PNMB $(\mathrm{R}=0.371, \mathrm{p}=0.07)$, Dominicalito y la Península de Osa $(\mathrm{R}=0.278, \mathrm{p}=0.11)$ y entre PNMB y la Península de Osa $(\mathrm{R}=0.149$, $\mathrm{p}=0.16$ ). En el Cuadro 5, se puede observar cuales especies contribuyeron más a la similitud en los sitios así como la disimilitud entre los mismos. Las especies que más diferenciaron los sitios fueron Prionurus laticlavius, Caranx caballus y Scarus ghobban (Cuadro 5).

\section{DISCUSIÓN}

\section{Cobertura del fondo y rugosidad:} ACOSA se puede dividir en términos de su cobertura del fondo y de la complejidad (rugosidad) de sus arrecifes en dos: localidades con una alta cobertura de coral y una moderada a baja cobertura de ACC (Golfo Dulce y RBIC), 


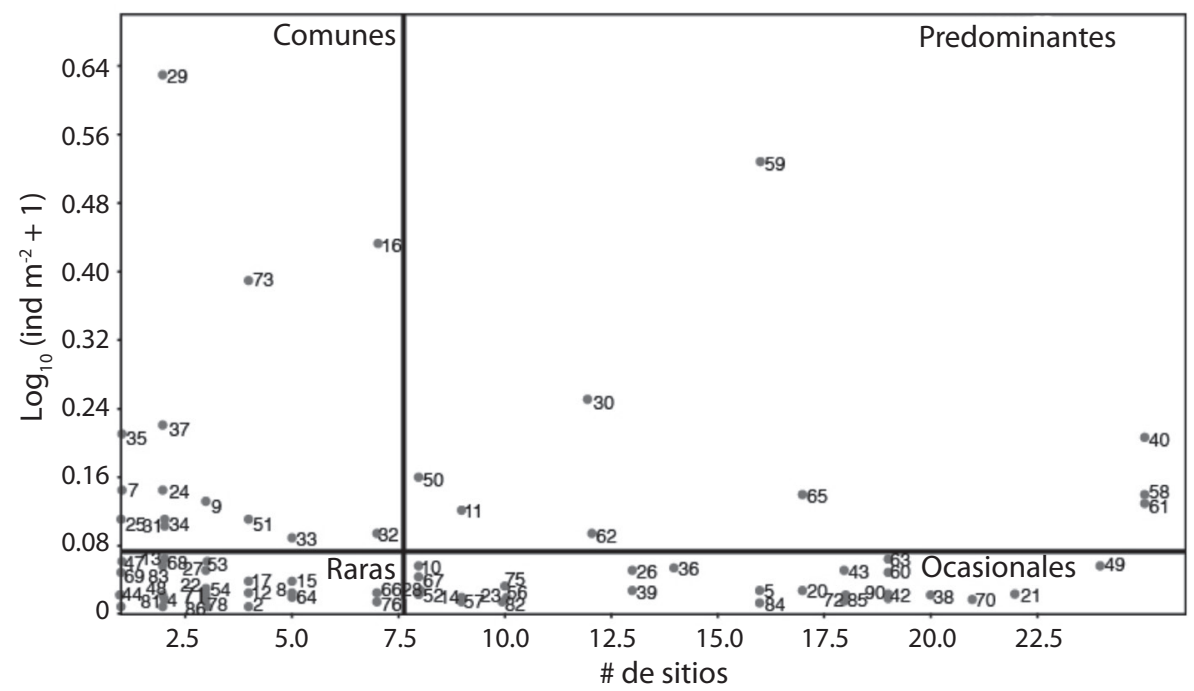

Fig. 6. Categorías de abundancia de peces arrecifales en ACOSA, basadas en la densidad (ind $\mathrm{m}^{-2}$ ) y la presencia (\# de sitios donde la especie fue observada) de todas las especies. Líneas negras gruesas indican el valor promedio de la densidad y de la ocurrencia. Número de las especies se puede observar en el Anexo 3.

Fig. 6. Reef fish abundance categories at Osa Conservation Area, based on densities (ind $\mathrm{m}^{-2}$ ) and occurrence (number of sites where the species was observed). Black bold lines show mean values of density and occurrence. Species numbers on digital appendix 3 .

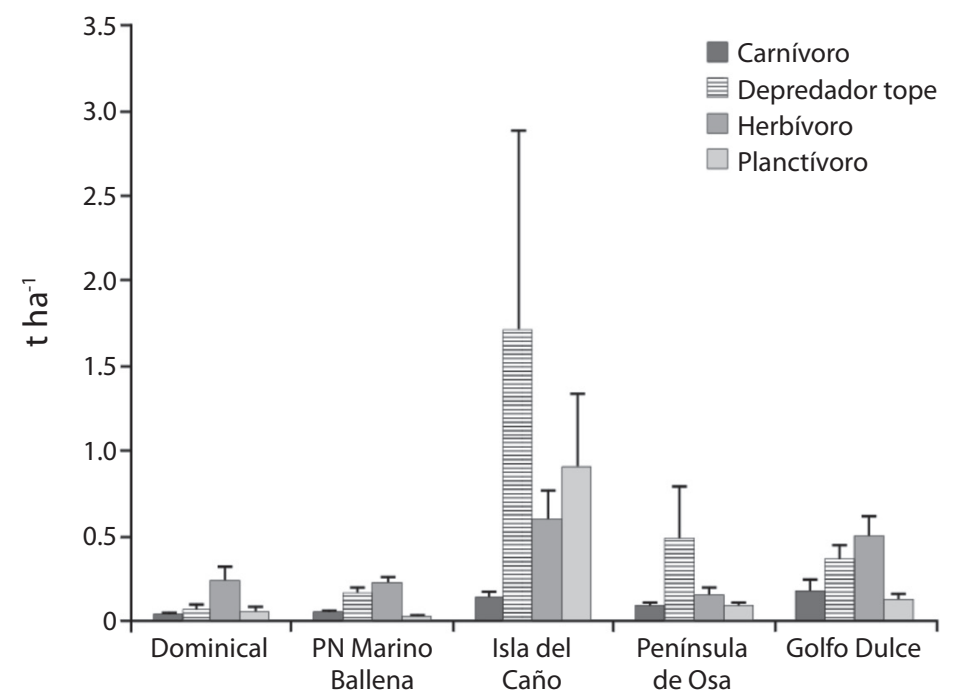

Fig. 7. Promedio (error estándar) de la biomasa de los grupos tróficos de peces por localidad de muestreo en el Área de Conservación Osa.

Fig. 7. Mean biomass (standard error) from fish trophic groups by sampled locality at Osa Conservation Area. 


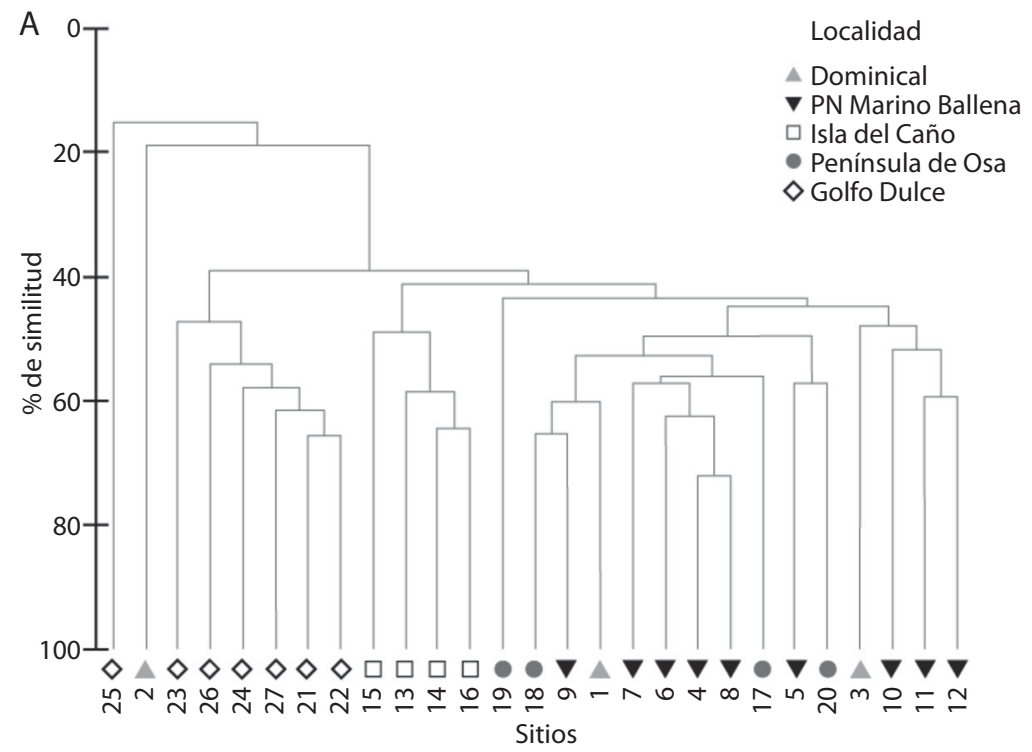

B
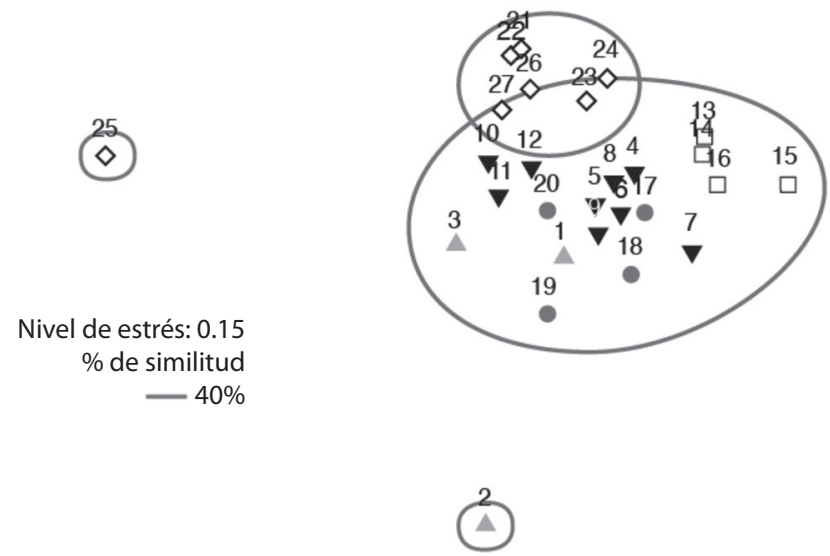

Fig. 8. A) Dendrograma de unión simple, B) análisis multidimensional escalado por factor localidad, basados en una matriz de similitud de Bray-Curtis utilizando los valores de biomasa de peces (transformados los datos con raíz cuadrada) en los sitios de muestreo en el Área de Conservación Osa. Número de los sitios se puede observar en el Cuadro 1.

Fig. 8. A) Hierarchical cluster analyses, B) Non metric multi-dimensional scaling analysis by locality factor, based on a Bray Curtis similarity matrix using fish biomass values (data square root transformed) in the sampled sites, at Osa Conservation Area. Sites numbers on Table 1.

y localidades con moderadas a bajas coberturas de coral y bajas coberturas de ACC (PNMB, Península de Osa y Dominicalito). Por su parte, Golfo Dulce sobresale de las otras localidades por tener arrecifes muy particulares (i.e Nicuesa: alta cobertura de coral Psammocora). La principal diferencia entre los dos sectores antes mencionados se debe probablemente a las condiciones adversas para el desarrollo de los arrecifes coralinos, en especial la sedimentación. Alvarado et al. $(2005,2009)$ han indicado que los arrecifes coralinos del PNMB se encuentran bajo la influencia y presión de una fuerte sedimentación debido a la escorrentía proveniente de la fila costeña que ha provocado la disminución en la cobertura de coral vivo. Esta, a su vez se ha deteriorado por el impacto del calentamiento de las aguas provocado 
CUADRO 5

Resultados del análisis de similitud porcentual (SIMPER) utilizando biomasa de peces arrecifales ( $\left.\mathrm{t} \mathrm{ha}^{-1}\right)$, para el periodo 2013-2014, en el Área de Conservación Osa (ACOSA)

TABLE 5

Reef fish species biomass $\left(\mathrm{t} \mathrm{ha}^{-1}\right)$ similarity percentages (SIMPER) analysis, in 2013 and 2014 at Osa Conservation Area

\begin{tabular}{|c|c|c|c|}
\hline Localidad & $\%$ Similitud & Especies & Contribución porcentual \\
\hline \multirow[t]{2}{*}{ Dominicalito } & $25.72 \%$ & Microspathodon dorsalis & $62.43 \%$ \\
\hline & & Pseudobalistes naufragium & $12.02 \%$ \\
\hline P.N. Marino Ballena & $28.57 \%$ & Pseudobalistes naufragium & $12.22 \%$ \\
\hline \multirow[t]{2}{*}{ R. B. Isla del Caño } & $29.24 \%$ & Scarus rubroviolaceus & $14.25 \%$ \\
\hline & & Caranx melampygus & $13.83 \%$ \\
\hline \multirow[t]{3}{*}{ Peninsula de Osa } & $20.20 \%$ & Pseudobalistes naufragium & $13.74 \%$ \\
\hline & & Caranx caballus & $13.43 \%$ \\
\hline & & Kyphosus sp. & $13.34 \%$ \\
\hline \multirow[t]{2}{*}{ Golfo Dulce } & $23.22 \%$ & Scarus ghobban & $29.29 \%$ \\
\hline & & Lutjanus argentiventris & $13.02 \%$ \\
\hline \multirow[t]{2}{*}{ Dominicalito-P. N. Marino Ballena } & $76.46 \%$ & Prionurus laticlavius & $7.65 \%$ \\
\hline & & Scarus perrico & $7.08 \%$ \\
\hline \multirow[t]{2}{*}{ Dominicalito-R. B. Isla del Caño } & $90.43 \%$ & Caranx caballus & $9.23 \%$ \\
\hline & & Prionurus laticlavius & $7.54 \%$ \\
\hline \multirow[t]{2}{*}{ P. N. Marino Ballena-Isla del Caño } & $80.88 \%$ & Caranx caballus & $9.75 \%$ \\
\hline & & Prionurus laticlavius & $6.59 \%$ \\
\hline \multirow[t]{2}{*}{ Dominicalito-Península de Osa } & 82.39 & Caranx caballus & $16.9 \%$ \\
\hline & & Pseudobalistes naufragium & $9.72 \%$ \\
\hline \multirow[t]{2}{*}{ P. N. Marino Ballena-Península de Osa } & $76.16 \%$ & Caranx caballus & $13.96 \%$ \\
\hline & & Pseudobalistes naufragium & $7.19 \%$ \\
\hline \multirow[t]{2}{*}{ R. B. Isla del Caño-Península de Osa } & $81.96 \%$ & Caranx caballus & $12.31 \%$ \\
\hline & & Prionurus laticlavius & $6.71 \%$ \\
\hline \multirow[t]{2}{*}{ Dominicalito-Golfo Dulce } & $91.39 \%$ & Scarus ghobban & $12.09 \%$ \\
\hline & & Microspathodon dorsalis & $8.57 \%$ \\
\hline \multirow[t]{2}{*}{ P. N. Marino Ballena-Golfo Dulce } & $81.12 \%$ & Scarus ghobban & $8.74 \%$ \\
\hline & & Lutjanus guttatus & $6.12 \%$ \\
\hline \multirow[t]{2}{*}{ Isla del Caño-Golfo Dulce } & $87.59 \%$ & Caranx caballus & $8.03 \%$ \\
\hline & & Prionurus laticlavius & $6.1 \%$ \\
\hline \multirow[t]{2}{*}{ Península de Osa-Golfo Dulce } & $85.94 \%$ & Caranx caballus & $11.44 \%$ \\
\hline & & Scarus ghobban & $8.56 \%$ \\
\hline
\end{tabular}

por el fenómeno de El Niño (Jiménez y Cortés, 2001, 2003). Mientras que Golfo Dulce muestra un estado de salud arrecifal mucho mejor que las otras localidades, y en relación a estudios anteriores, donde se evidenciaba que esta zona era altamente afectada por la sedimentación (Cortés, 1990, 1991, 1992). Esta diferencia, probablemente gracias al beneficio que las estrategias de conservación (i.e. compra de tierras, pago por servicios ambientales, practicas de turismo rural comunitario, entre otras) en la región han tenido en aumentar la cobertura boscosa en las áreas alrededor del golfo, como el mejor manejo de la actividad forestal en la Reserva Forestal Golfo Dulce, lo cual ha generado una disminución en la entrada de sedimentos al golfo. 
La cobertura coralina se ha ido modificando a través del tiempo tanto negativamente como positivamente en cada una de las localidades. En Dominicalito, en 1992 y 1994, Jiménez y Cortés $(2001,2003)$ reportan una cobertura de coral vivo de $24.8 \pm 11.6 \%$ y $29 \pm 3.5 \%$ respectivamente, para Punta Cambutal (sitio El Arbolito \#2), donde predominada Porites lobata. Sin embargo, como efecto de El Niño del 2001 la cobertura disminuyó a $21.2 \pm 3.4 \%$ (Jiménez y Cortés, 2003). En nuestra evaluación la cobertura actual es de $8.65 \%$, siendo significativamente diferente a la descrita en los estudios previos $\left(\mathrm{F}_{3,17}=29.939, \mathrm{p}<0.01\right)$, lo que indica que las presiones (i.e. contaminación, sedimentación) sobre los arrecifes posiblemente se han mantenido o aumentando y han causado un mayor deterioro en esta zona arrecifal.

Para el PNMB, Jiménez y Cortés (2001, 2003) indican un comportamiento similar con la cobertura de coral vivo, específicamente para el área noreste del tómbolo. Jiménez y Cortés (2001) observan una disminución paulatina en la cobertura de coral vivo de $22.0 \pm 6.2 \%$ en 1992 a $14.8 \pm 1.8 \%$ en el año 2001 (sitio Tómbolo NE\#2), comportamiento atribuido a la mortandad como producto del fenómeno de El Niño de 1997-1998. Actualmente, se determinó una cobertura de $9.26 \%$ en este sitio, la cual es estadísticamente diferente $\left(\mathrm{F}_{3,62}=27.305, \mathrm{p}<0.001\right)$ a la observada en años anteriores, e indicando que la disminución continúa. Esto hace pensar que la cobertura previa a El Niño de 1997-1998 era alta en la zona y que ha disminuido notablemente, pero que no ha logrado recuperarse por el efecto de la sedimentación sobre estos arrecifes (Alvarado et al. 2009). Por su parte, para sitios como Tómbolo NE\#1, Alvarado et al. (2005, 2009) y Cortés et al. (2010), indican que la cobertura osciló entre 2-6\% entre el 2003 y el 2008; y para el 2013/2014, se determinó una cobertura de $7.14 \%$ similar a los otros años $\left(\mathrm{F}_{6,17}=0.530, \mathrm{p}=0.778\right)$.

Para otro sector del PNMB, específicamente en el sitio Las Tres Hermanas, Alvarado et al. (2005, 2009) y Cortés et al. (2010) informan de una cobertura de coral vivo promedio, entre los años 2003 a 2008 , de $26.1 \pm 1.9 \%$ a $39.8 \pm 18.2 \%$. En el 2013/2014, la cobertura fue $24.05 \%$, sin observarse diferencias significativas entre los años $\left(\mathrm{F}_{6,23}=0.867, \mathrm{p}=0.53\right)$. Esto indica que este sitio se ha mantenido estable a través del tiempo, y que el efecto de la sedimentación posiblemente no es tan fuerte. En los sitios mencionados, predomina el coral $P$. lobata, que es una especie con mayor resistencia a la sedimentación (ver referencias en Alvarado et al., 2009), mientras que la presencia de especie ramosas como Pocillopora es baja.

En el PNMB, destaca el arrecife coralino de Bajo Mauren, donde predomina el coral Pavona clavus. La presencia de los arrecifes de esta especie es particular ya que este son escasos en el Pacífico Tropical Oriental (PTO) (Cortés \& Jiménez, 2003), por lo que deben continuar siendo estudiados para monitorear su condición en el tiempo.

Para la Isla del Caño, Guzmán et al. (1987) y Guzmán y Cortés $(1989,2001)$ describen el comportamiento de la cobertura de coral vivo entre 1980 y 1998, indicando dos periodos de pérdida fuerte en la cobertura coralina. El primero entre 1980 y 1984 (Guzmán et al., 1987), luego de una fuerte mortalidad coralina producto del fenómeno de El Niño de 1982-1983, pasando de $17.8 \pm 7.17 \%$ de coral vivo en 1980 a $8.55 \pm 5.13 \%$ en 1984 . Este mismo estudio, reporta que en 1985, se da una recuperación en la cobertura de coral $(15.0 \pm 13.0 \%)$, sin embargo, entre junio y agosto de ese año, se presentó una severa mortandad coralina por efecto de floraciones algales nocivas (Guzmán \& Cortés, 1989; 2001). Entre 1987 y 1999, varios eventos de El Niño produjeron blanqueamiento, pero la mortalidad fue menor en todas las profundidades, permitiendo que la cobertura se mantuviera constante entre $7-11 \%$. En contraste, el presente análisis determina que para 2013/2014 la cobertura promedio de coral vivo para la Isla del Caño es de $21.18 \pm 11.90 \%$, siendo significativamente superior a la observada en otros años $\left(\mathrm{F}_{3,135}=7.204, \mathrm{p}<0.001\right)$. Esto evidencia que los arrecifes de la RBIC se han recuperado a través del tiempo, permitiéndole alcanzar 
coberturas similares a las observadas previas a El Niño de 1982-1983. A pesar de este buen estado de conservación, se observó la presencia de parches grandes del alga invasora Caulerpa sertulariodes, sobre todo en la parte noroeste de la Isla, lo que puede significar una nueva amenaza para los arrecifes de esta localidad. Esto debe considerarse en las acciones de gestión del área, debido a que en la RBIC y en esta zona específica de la isla, se encuentra el alga coralina endémica Porolithon castellum (Robinson et al., in prep.).

En la Península de Osa, se ha reportado la presencia de arrecifes coralinos en San Josecito, San Pedrillo, Punta Salsipuedes y Punta Llorona (Cortés \& Jiménez, 1996, 2003). Por su parte, en 1994 Cortés y Jiménez (1996) realizaron transectos en Punta Salsipuedes, Punta Media y Río Claro. Particularmente en San Pedrillo encuentran tres parches pequeños de Pocillopora spp. (Cortés \& Jiménez, 1996) y un arrecife de aproximadamente $250 \mathrm{~m}^{2}$ con una cobertura viva cercana al $100 \%$ de Pocillopora damicornis (Cortés \& Jiménez, 2003). En Punta Salsipuedes y San Pedrillo se describen cinco y 11 especies de coral, respectivamente (Cortés \& Jiménez, 1996). En nuestra evaluación, San Pedrillo tenía una cobertura baja de coral (2.85\%), mientras que en San Josecito determinamos una zona arrecifal bastante amplia $\left(\sim 9000 \mathrm{~m}^{2}\right)$ con una cobertura de $37.8 \%$, siendo inclusive más que las observadas en la Isla del Caño, lo que le da particular importancia en términos de conservación. Sin embargo, este sitio es altamente visitado por tour operadores, los cuales llevan turistas en grandes cantidades a esnorquelear al arrecife sin que haya ningún control de las actividades en esta zona, lo que puede poner en riesgo la calidad de este arrecife.

Finalmente, para el Golfo Dulce, se ha visto que la cobertura de coral vivo a través del tiempo ha sido variable. En Punta Islotes, se observó un incremento en la cobertura entre $1985-1987$ y 1997 , pasando de $1.7 \pm 2.3 \%$ a $9.9 \pm 6.6 \%$. Mientras, en el arrecife de Sándalo se dio una disminución de $29.1 \pm 20.2 \%$ a $16.7 \pm 19.8 \%$, en el mismo periodo (Cortés,
1990, 1992; Fonseca et al., 2006). Se encontró para el sitio Islotes una cobertura de $17.6 \%$, y en promedio para los dos sitios de Sándalo una cobertura de $27.9 \pm 18.3 \%$, siendo en ambos casos significativo el aumento en la cobertura coralina $\left(\mathrm{F}_{2,50}=24.29, \mathrm{p}<0.001 ; \mathrm{F}_{2,50}=2.281\right.$, $\mathrm{p}<0.001$, respectivamente). Esta recuperación en los arrecifes de Golfo Dulce es aún más evidente para el arrecife en Punta Nicuesa. Cortés $(1990,1992)$ reportó una cobertura de coral vivo de $45.9 \pm 35.0 \%$ para el periodo de $1985 / 1988$, mientras que aquí se reporta una cobertura de $83.4 \%$, siendo significativo el incremento en la cobertura coralino de este sitio $\left(\mathrm{F}_{1,15}=12.341, \mathrm{p}<0.001\right)$. Este arrecife está compuesto casi en un $100 \%$ por el coral Psammocora stellata. Arrecifes de este tipo eran comunes en el Pacífico Norte de Costa Rica, en Bahía Curú o en Bahía Culebra (Cortés \& Jiménez, 2003; Bezy et al., 2006). Sin embargo, en la actualidad están todos muertos o deteriorados, dándole un alto valor de conservación al de Nicuesa por ser uno de los pocos que existe a lo largo del PTO.

Diversidad y abundancia de macroinvertebrados: Hay pocas investigaciones sobre las comunidades de macroinvertebrados de ACOSA. En el Golfo Dulce, Dominicalito y la Península de Osa son inexistentes, en la RBIC se realizó un trabajo enfocado en organismos coralívoros y bioerosionadores (Guzmán, 1998), mientras que en el PNMB se estudiaron la diversidad y abundancia de equinodermos (Alvarado \& Fernández, 2005). La escasez de información ha imposibilitado la comparación de estas comunidades a través del tiempo. Este trabajo presenta una línea base, que permitirá conocer la dinámica de las comunidades de macroinvertebrados de ACOSA con futuras investigaciones.

En el presente trabajo, los equinoideos D. mexicanum y E. thouarsii fueron los organismos predominantes (Fig. 4). Esto es comparable al resultado obtenido por Alvarado, Guzmán y Breedy (2012a), en el Golfo de Chiriquí, Panamá, donde estas especies presentaron mayor densidad. La densidad promedio de 
D. mexicanum en Chiriquí no superó 1 ind $\mathrm{m}^{-2}$, y se asemeja a la encontrada en Golfo Dulce (1ind $\mathrm{m}^{-2}$ ). Anteriormente, se había notando similitud en la composición geológica entre los arrecifes coralinos del Golfo Dulce y los del Golfo de Chiriquí (Cortés, 1991), por lo que es posible que la formación y composición del arrecife influye en la estructura de las comunidades de invertebrados. Para San Juan del Sur, Nicaragua (Alvarado et al., 2011b), y la isla del Coco, Costa Rica (Alvarado \& Chiriboga, 2008), los valores de densidad promedio rondan 1 ind $\mathrm{m}^{-2}$, y son similares a los observados en este trabajo

En una investigación realizada en el 2004, en el PNMB, D. mexicanum no estuvo presente en los sitios Las Tres Hermanas ni en la Isla Ballena (Alvarado \& Fernández, 2005), mientras que en el presente estudio se encontró en todos los sitios del PNMB (Anexo 2). Esta mayor incidencia de este erizo, es posible que se deba a un aumento en la cobertura de tapete algal y a una posible disminución en el impacto de la sedimentación sobre esta zona. Este erizo presenta hábitos herbívoros al encontrarse en bajas densidades, controlando las poblaciones de macroalgas, sin embargo en agregaciones mayores sus hábitos se vuelven bioerosionadores, alterando y disminuyendo la complejidad estructural del arrecife (Sammarco, 1980, 1982; Alvarado, Cortés \& Reyes-Bonilla, 2012b).

En la RBIC, Guzmán (1988) encontró para 1985 una densidad de Acanthaster planci de 0.86 ind ha ${ }^{-1}$ (ámbito 0.37-1.33ind ha ${ }^{-1}$ ), mientras que para 1986 encuentra 1.22 ind ha $^{-1}$. En el presente estudio, A. planci muestra una densidad más alta $\left(160 \pm 270\right.$ ind $\left.\mathrm{ha}^{-1}\right)$, y se asume que esta diferencia pudo haber sido ocasionada por emplear diferentes métodos de muestreo. Entre 1985 y 1986, Guzmán (1988) observó un aumento en la densidad de los erizos de mar $D$. mexicanum $\left(1.15\right.$ ind $\mathrm{m}^{-2}$ y 3.9 ind $\mathrm{m}^{-2}$, respectivamente) y E. thouarsii $\left(0.71\right.$ ind $\mathrm{m}^{-2}$ y 2.15 ind $\mathrm{m}^{-2}$ ). Contrario a lo observado con $A$. planci, en el presente estudio, D. mexicanum (0.46ind $\left.\mathrm{m}^{-2}\right)$ y E. thouarsii $\left(0.21\right.$ ind $\left.\mathrm{m}^{-2}\right)$ presentan densidades menores a las registradas por Guzmán (1988). Alvarado et al. (2012b) indican las densidades de $D$. mexicanum observadas en RBIC en $1980\left(0.27\right.$ ind $\left.\mathrm{m}^{-2}\right), 1984$ (0.46 indm $\left.{ }^{-2}\right), 2007$ (0.09ind $\left.\mathrm{m}^{-2}\right)$ y 2009 (0.28ind $\mathrm{m}^{-2}$ ). A pesar que se ha observado un aumento en la cobertura coralina de la RBIC (ver sección Cobertura de fondo y rugosidad), hoy $D$. mexicanum alcanza densidades tan altas como las registradas al finalizar El Niño de 19821983. Sin embargo, sus densidades no son consideradas como un riesgo para la isla, sino son un indicativo de salud arrecifal (Alvarado et al., 2012b).

El cambute (Lobatus galeatus) es una especie que cuenta con poca regulación de extracción, y que en el presente estudio resultó ser común en varios sitios. Arroyo-Mora (2008) informa un ámbito entre 47-1 364 ind ha ${ }^{-1}$ para el PNMB en muestreos realizados en 1999, 2001 y 2003, y los factores que determinaron la abundancia de este caracol fueron el sitio y la época lluviosa. La densidad promedio para el PNMB encontrada en el presente trabajo es de 781 ind ha $^{-1}$, siendo los sitios más poblados el Bajo Tres Hermanas, Tres Hermanas e Isla Ballena (Anexo 2). Se asume que la población del PNMB se encuentra protegida (ArroyoMora, 2008). Sin embargo, la actividad extractiva ilegal de esta especie puede ser que esté causando una disminución en sus poblaciones (observación personal).

Diversidad y biomasa de peces: La riqueza de peces de ACOSA es bastante diversa en términos comparativos versus otras zonas del país o de la región. En términos regionales, su diversidad es intermedia si se toma como parámetro superior las Islas Galápagos con 175 especies (Edgar, Banks, Farinha, Calvopinha \& Martínez, 2004), y como valor inferior la zona de San Juan del Sur en Nicaragua con 52 especies (Alvarado et al., 2011b). En el Golfo de Chiriquí, Panamá, una zona cercana a ACOSA, Dominici-Arosemena y Wolff (2006) informan la presencia de 126 especies de peces arrecifales, mientras que para el Archipiélago de las Perlas, se reporta un total de 79 especies (Benfield, Baxter, Guzman \& Mair, 2008). A nivel nacional la riqueza de especies de 
ACOSA se puede comparara con la Isla del Coco, que posee un total de 94 especies asociadas a sus ecosistemas arrecifales (Alvarado et al., in prep.), siendo muy superior a lo reportado para otras zonas como las Islas Catalinas con 46 especies (Espinoza \& Salas, 2005) o Bahía Culebra con 75 especies (DominiciArosemena, Brugnoli-Olivera, Cortés-Núñez, Molina-Ureña \& Quesada-Alpízar, 2005).

Los estudios relacionados a la ictiofauna de ACOSA, se han concentrado principalmente en Golfo Dulce (Quesada-Alpízar \& Cortés, 2006), con escasos trabajos para el resto del área. Previo a esta investigación, no existían trabajos para la zona de Dominicalito o la Península de Osa. En este estudio, Dominicalito fue la localidad menos diversa (26 especies), con menores biomasas de grupos tróficos altos y medios, y presenta una comunidad de peces mayormente representada por herbívoros (Fig. 6). Esto podría ser un indicador de impacto sobre las comunidades debido a la eliminación de especies depredadoras por su importancia comercial (Friedlander \& DeMartini, 2002). El sitio Dominicalito se encuentra fuera de cualquier área protegida, en los alrededores de una comunidad de pescadores, por lo cual al cerrarse las actividades extractivas en el PNMB es posible que esta zona se volviera un foco de presión pesquera convirtiéndose en una amenaza para la conservación de los recursos (CoopeSolidar, 2002). Asimismo, la zona es influenciada por la alta sedimentación y escorrentía que viene de la fila costeña en época de lluvias (Alvarado et al., 2009). Todo esto se ve reflejado en el deterioro de los sitios en la localidad de Dominicalito, con bajas coberturas coralinas y bajas diversidades de peces e invertebrados.

Para la Península de Osa, se reportan un total de 47 especies de peces (Anexo 3). Es necesario desarrollar un estudio complementario que apoye el análisis de especies en la parte externa de la Península de Osa. Además, es necesario analizar el efecto de la actividad pesquera en esta localidad (Guzmán-Mora, 2012). Esto permitirá evidenciar si el área marina protegida del Parque Nacional Corcovado, que sólo tiene una franja de $500 \mathrm{~m}$ de protección, debe de ampliarse para proteger otros sitios que poseen un alto valor ictiológico o arrecifal (i.e. Piedra Llorona).

La ictiofauna del PNMB ha sido pobremente estudiada. Salas y Alvarado (2008) presentaron una lista de 54 especies asociadas a arrecifes. En la presente investigación, se observaron 64 especies, de las cuales Gymnothorax castaneus, Muraena lentiginosa, Prionurus punctatus, Gnathanodon speciosus, Lutjanus novemfasciatus, Lutjanus viridis, Pseudupeneus grandisquamis, Alphestes immaculatus, Dermatolepis dermatolepis, Scorpaena mystes y Balistes polylepis no habían sido reportadas en el trabajo previo. Salas y Alvarado (2008), reportan la presencia de Kyphosus sp., mientras que en el presente análisis se identifican las dos especies de este género: $K$. analogus y $K$. elegans. Entre las dos investigaciones, se reporta un total de 66 especies de peces arrecifales asociadas a las aguas del PNBM. Para esta localidad, en el presente trabajo, Bajo Mauren (un arrecife formado por Pavona) fue el sitio con mayor riqueza en el PNMB (40 especies). La Viuda se mantiene como uno de los sitios con mayor riqueza de la localidad (21 especies en 1999-2004 y 36 especies en 2013-2014) (Anexo 3). Llama la atención que este sitio se encuentra fuera de los límites del PNMB. Sin embargo, presenta alta diversidad debido posiblemente a su estructura rocosa y a la influencia que tiene el área protegida sobre el sitio. En general, las biomasas de peces en la localidad fueron bajas y la estructura de grupos tróficos asemeja lo encontrado en Dominicalito. Esto podría indicar que además de la pesca, el deterioro de los ambientes arrecifales que se ha dado en el PNMB está afectando también las comunidades peces, disminuyendo la complejidad estructural y por tanto el acceso a refugio para los organismos.

Guzmán (1988) fue el primero en estudiar los peces arrecifales en la Isla de Caño, dando la densidad de especies de coralívoros, como Arothron meleagris, A. hispidus, Sufflamen verres, Pseudobalistes naufragium, Microspathodon dorsalis, y Stegastes acapulcoensis. 
Posteriormente, Cortés et al. (2009) presentan una lista de especies de peces de esta isla (82 especies.), y más recientemente Salas, Sánchez-Godínez y Montero-Cordero (2014) hacen un análisis de la composición de las comunidades y dan una lista actualizada de los peces arrecifales de la RBIC. De acuerdo a todos los indicadores utilizados en el presente estudio, los sitios de la Isla del Caño fueron los más diversos de toda ACOSA. Esta alta diversidad ha sido observada por Salas, Sánchez-Godínez y Montero-Cordero (2015), quienes reportan una riqueza de 212 especies que representa aproximadamente un $17 \%$ de la diversidad de peces del Pacífico Tropical Oriental. La RBIC presenta altas biomasas de peces, principalmente en los niveles tróficos altos (Fig. 7), con la presencia de especies de importancia en la conservación como el tiburón punta blanca de arrecife (Triaenodon obesus) o el tiburón toro (Carcharhinus leucas) (Cortés et al., 2009), considerados como casi amenazados en la Lista Roja de la UICN. La dominancia de depredadores tope y planctívoros ya se ha observado para otros lugares con protección contra la pesca y refleja un acercamiento al comportamiento natural de los ecosistemas coralinos en ausencia del actividades humanas (Friedlander et al. 2012), por lo cual es esencial mantener o mejorar la protección que se le da a la zona marina de la RBIC.

Con respecto a la ictiofauna de Golfo Dulce, se han realizado varias investigaciones (Campos, 1989; Cortés, 1992; Bussing \& López, 1996; Wolf, 1996; Rojas-Figueroa, 2001; Quesada-Alpízar, Cortés, Alvarado \& Fonseca, 2006; Guzmán-Mora, 2012) de las cuales solo la de Cortés (1992) y Rojas (2001) contemplaron la fauna asociada a arrecifes coralinos. Cortés (1992) realizó observaciones en una zona del arrecife de Punta Islotes y en siete secciones de Sándalo, entre febrero 1985 y marzo 1989, reconociendo en total 24 especies de peces. Rojas (2001) determinó la abundancia y distribución de 71 especies de peces asociados a arrecifes coralinos, donde Halichoeres melanotis, $H$. chierchiae y Caranx sexfasciatum representaron el 56\% de la abundancia. A pesar de esto, estas especies no se observaron durante nuestra investigación, por lo cual, actualmente deben ser especies poco comunes (o ausentes) en los arrecifes coralinos del Golfo Dulce. El jurel C. sexfasciatum es una especie de importancia comercial y es capturada ocasionalmente por los pescadores artesanales de la zona (Guzmán-Mora, 2012), por lo que su extracción podría contribuir a la disminución en la abundancia o presencia de esta especie en los arrecifes del Golfo. Las especies Gymnothorax castaneus, Myripristis berndti, Acanthurus xanthopterus, Elacatinus punticulatus, Halichoeres dispilus, Malacoctenus zonifer, Scarus rubroviolaceus, Dermatolepis dermatolepis, Rypticus nigripinnis, Zanclus cornutus y Arothron meleagris no habían sido reportadas anteriormente para los arrecifes del Golfo Dulce, por lo cual el número de especies asciende a 82 . Este es el primer registro de estas especies para la zona, pero estas se encuentran dentro del rango de distribución ya conocido para ellas (Allen \& Robertson, 1994). La composición de peces del Golfo Dulce difirió con respecto a las demás localidades (Fig. 8, Anexo 3). Scarus ghobban es una de las especies predominantes en esta localidad y también es de las que más contribuyó a la diferencia con las otras localidades (Cuadro 5). Este pez, es una especie herbívora (Allen \& Robertson, 1994), que puede estar contribuyendo con la baja cobertura de macroalgas en los arrecifes del Golfo (Fig. 2, Anexo 1). Las macroalgas son bien conocidas como competidoras con los corales (McCook, Jompa \& Díaz-Pulido, 2001), por lo tanto la presencia de especies herbívoras como $S$. ghobban puede liberar a los arrecifes de esa presión. Las biomasas de peces presentes en Golfo Dulce mostraron valores intermedios entre la RBIC y las zonas impactadas como Dominicalito y PNMB, sin embargo también presenta una dominancia de herbívoros debida posiblemente a la pesca. Los pescadores enfocan sus esfuerzos en especies no herbívoras como L .guttatus y L. peru. Es importante realizar monitoreos de las comunidades de peces del Golfo Dulce para poder determinar las variaciones en su estructura 
trófica, de esa manera evaluar el efecto del Área Marina de Pesca Responsable sobre los ecosistemas arrecifes del Golfo.

Necesidades de conservación: El Área de Conservación Osa encierra una alta diversidad en sus ecosistemas arrecifales, donde se observa un incremento en mejores prácticas de conservación que están beneficiado estos ecosistemas. Asimismo, es notable como las áreas marinas protegidas de esta zona del país, están teniendo una influencia real sobre el desarrollo de especies claves. Esto sin duda, es resultado de una mayor conciencia ambiental en la región, una mayor apropiación sobre la riqueza marina que poseen y participación en las acciones de conservación por parte de las comunidades. Sin embargo, los resultados presentados en este estudio evidencian la necesidad de fortalecer y desarrollar estrategias complementarias de conservación efectiva de las AMPs de ACOSA.

Los resultados en el sector de Dominicalito, reflejan la necesidad de realizar un trabajo fuerte con las comunidades aledañas a la zona para mejorar la condición de los ecosistemas coralinos de este sitio. Esta zona es la más deteriorada de ACOSA, lo que puede ser efecto de presiones o disturbios que no han sido bien manejados en la región, como la presión pesquera y el desarrollo inmobiliario, asociado a un mal manejo de cuencas.

Actividades humanas como el desarrollo inmobiliario y el manejo adecuado de cuencas, deben seguir siendo una prioridad en los alrededores del PNMB y en toda ACOSA en general. Es necesario controlar el impacto que causa la sedimentación sobre los arrecifes coralinos más cercanos a la costa, así como de la pesca furtiva que ocurre en la noche. Es importante buscar los mecanismos para integrar al PNMB la roca La Viuda que posee una riqueza excepcional de abanicos de mar, así como de otros organismos.

Para la RBIC, es necesario iniciar un programa de monitoreo y erradicación del alga invasiva Caulerpa sertularioides, la cual en la actualidad se encuentra muy localizada en un sector de la isla. Sin embargo, si las condiciones llegaran a favorecer su crecimiento (i.e. eutrofización desmedida), esta puede llegar a ser muy agresiva en su desarrollo, sobrecreciendo los corales y provocando una disminución en la diversidad de las especies asociadas al arrecife.

Para el sector de la Península de Osa, es necesario regular las actividades turísticas en San Josecito, donde se encuentra un arrecife muy saludable, pero que por el momento no posee ninguna propuesta de manejo. En este sentido, es necesario evaluar cuál sería la herramienta de manejo más efectiva para que siga permitiendo una actividad turística controlada y favorezca la conservación del arrecife. En el caso de la Piedra Llorona, es importante buscar los mecanismos para incluirla dentro del PNC, tratando de ampliar la protección marina de este parque, que en la actualidad es de solo $500 \mathrm{~m}$.

Dentro de Golfo Dulce, y debido al importante arrecife de Psammocora, se recomienda incluirlo dentro del PNPB en una franja marina de al menos $200 \mathrm{~m}$ desde el borde costero de este parque, para que proteja los sitios Punta Adela, Nicuesa y Punta Gallardo. O establecer una zonación particular dentro del Área de Pesca Responsable Golfo Dulce, donde estos tres sitios estén en una zona de no usos extractivos. En estas zonas es importante colocar boyas para que los arrecifes no se vean impactados por las anclas de las lanchas. De igual forma, para los sitios Mogos, Islotes y Sándalo (1 y 2), se debe realizar una zonación y manejo similar al menciona anteriormente dentro del AMPR Golfo Dulce.

Tanto para Golfo Dulce, como para el resto de las localidades estudiadas en el presente trabajo, es necesario continuar con el monitoreo a largo plazo. Un manejo efectivo del ambiente requiere programas de monitoreo que provean las conexiones especificas entre las condiciones ambientales y la salud del ecosistema (Cooper, Gilmour \& Frabricius, 2009). El monitoreo se convierte en una herramienta fundamental para detectar los cambios naturales y aquellos provocados por el Hombre sobre dicha biodiversidad (Velarde, 2004), así como 
proveer información de la respuesta del sistema a las acciones de manejo (Yoccoz, Nichols \& Boulinier, 2001). El monitoreo de la biodiversidad percibe los cambios generales en la composición de las comunidades arrecifales como subrogados de la salud del ecosistema y por lo tanto provee un medio para rastrear cambios en la biodiversidad (Kremen, Merenlender, \& Murphy, 1994). Además, provee a los tomadores de decisión con comparaciones cuantitativas de la respuesta de la biodiversidad (Kremen et al., 1994) ante diferentes actividades humanas que la puedan o no estar afectando.

\section{AGRADECIMIENTOS}

La presente investigación no se hubiera podido realizar sin el apoyo en campo de las siguientes personas: K. García, J. Sibaja, C. Sánchez, V. Bogantes, C. Salas, A. Suárez, J. Nivia, A. Quesada, N. Sandoval, J.C. Azofeifa, F. García y J.J. Fernández. Asimismo, el trabajo se vio fortalecido por el apoyo de F. Monge, Gorrión Tours, Taboga, A. Vargas, D. Vargas, Cabinas Mar y Luna, Hotel la Perla de Bahía, colegas del CIMAR y funcionarios de ACOSA. Un especial agradecimiento a Conservación Internacional por creer en este tipo de investigaciones. Este proyecto contó con el apoyo financiero de Conservación Internacional y del CIMAR. Asimismo, contó con el aval del SINAC a través de la resolución 015-2013, y se encuentra inscrito en FUNDEVI (2739-019) y en Vicerrectoría de Investigación de la Universidad de Costa Rica (808-B3-503). Este trabajo fue enriquecido por los valiosos comentarios de tres revisores anónimos.

\section{RESUMEN}

Costa Rica es considerado uno de los 20 países del mundo con mayor biodiversidad, entre los que destacan sus ecosistemas arrecifales. Más precisamente, el Pacífico Sur, el Área de Conservación Osa, se ha considerado como una de las zonas más diversas en estos ecosistemas. Estos arrecifes han sido estudiados desde inicios de los años 80's, pero enfocándose solamente en la cobertura coralinos de estos arrecifes. Por lo tanto, la presente investigación busca realizar una evaluación actualizada y con una metodología estándar él estado de varios componentes de los sistemas arrecifales de esta región. Entre el 2013 y el 2014, se visitaron cinco localidades: Dominicalito, Parque Nacional Marino Ballena, Reserva Biológica Isla del Caño, Península de Osa y Golfo Dulce, donde se evaluaron 27 sitios. En ellos se realizó la evaluación, a dos profundidades, de: cobertura del fondo, rugosidad del arrecife, diversidad y densidad de macroinvertebrados, así como la diversidad y biomasa de peces arrecifales. En términos generales los arrecifes de ACOSA, son moderadamente complejos y en ellos predominan el tapete algal $(62.7 \%)$, mientras que la cobertura de coral vivo es moderada (16.5\%). Se observó una diferencia entre la cobertura de tipos de sustratos por localidad, la cual puede estar atribuida a condiciones ambientales adversas (i.e. sedimentación, contaminación) para su desarrollo. Sin embargo, los arrecifes coralinos de Golfo Dulce e Isla del Caño muestran una notable recuperación al compararla con estudios previos. Se observaron 35 taxa de macroinvertebrados en los sitios estudiados, en su mayoría (58\%) fueron poco abundantes u ocasionales. La mayor diversidad y densidad de macroinvertebrados se observó en Golfo Dulce y se determinaron diferencias significativas entre localidades. Este estudio brinda una línea base para muchos de estos organismos en varios de los sitios. Los equinoideos Diadema mexicanum y Eucidaris thouarsii fueron los organismos predominantes, y se reporta el cambute (Lobatus galeatus) en varios de los sitios de muestreo. De las 90 especies de peces, 10 fueron las de mayor ocurrencia y densidad. No hubo diferencias significativas en la diversidad y riqueza de especies de peces observadas entre localidades, pero si en la biomasa y en la composición de la comunidad íctica entre los sitios. Los sitios de la Isla del Caño fueron los más diversos de toda ACOSA, presentan biomasas importantes y de niveles tróficos altos. Mientras que Golfo Dulce difirió con respecto a las demás localidades. Según los resultados observados, los arrecifes de ACOSA presentan una alta biodiversidad. Las condiciones del de los ecosistemas indican que más esfuerzos de conservación, uso sostenible y manejo efectivo de loa recursos en tierra como en el mar deben ser implementados. El monitoreo ecológico va a proveer de la información sobre las tendencias y las relaciones entre el estado de los ecosistemas arrecifales y las condiciones ambientales.

Palabras clave: Comunidad coralina, arrecife, biomasa, diversidad, abundancia, Pacífico Tropical Oriental.

\section{REFERENCIAS}

Allen, G. R., \& Robertson, D. R. (1994). Fishes of the Tropical Eastern Pacific. Hawaii: Hawaii University Press.

Alvarado, J. J., \& Fernández, C. (2005). Equinodermos del Parque Nacional Marino Ballena, Pacífico, Costa Rica. Revista de Biología Tropical, 53 (Supl. 3), 275-284. 
Alvarado, J. J., Cortés, J., Fernández, C., \& Nivia, J. (2005). Comunidades y arrecifes coralinos del Parque Nacional Marino Ballena, costa del Pacífico de Costa Rica. Ciencias Marinas, 31, 641-651.

Alvarado, J. J., \& Chiriboga, A. (2008), Distribución y abundancia de equinodermos en las aguas someras de la Isla del Coco, Costa Rica (Pacífico Oriental). Revista de Biología Tropical, 56 (Supl. 2), 99-111.

Alvarado, J. J., Fernández, C., \& Cortés, J. (2009). Water quality conditions on coral reefs at the Marino Ballena National Park, Pacific Costa Rica. Bulletin of Marine Science, 84, 137-152.

Alvarado, J. J., Herrera, B., Corrales, L., Asch, J., \& Paaby, P. (2011a). Identificación de las prioridades de conservación de la biodiversidad marina y costera en Costa Rica. Revista Biología Tropical, 59, 829-842.

Alvarado, J. J., Ayala, A., Álvarez del Castillo-Cárdenas, P. A., Fernández, C., Aguirre-Rubí, J., Buitrago, F., \& Reyes-Bonilla, H. (2011b). Coral communities of San Juan del Sur, Pacific Nicaragua. Bulletin of Marine Science, 87, 129-146.

Alvarado, J. J., Cortés, J., Esquivel, M. F., \& Salas, E. (2012). Costa Rica's Marine Protected Areas: status and perspectives. Revista de Biología Tropical, 60 129-142.

Alvarado, J. J., Guzman, H. M., \& Breedy, O. (2012a). Distribution and diversity of echinoderms (Asteroidea, Echinoidea, Holothuroidea) in the Islands of the Gulf of Chiriqui, Panama. Revista de Biología Marina y Oceanografia, 47, 13-22.

Alvarado J. J., Cortés, J., \& Reyes-Bonilla, H. (2012b). Reconstruction of Diadema mexicanum A. Agassiz, 1863 bioerosion impact on three Costa Rican Pacific coral reefs. Revista de Biología Tropical, 60 (Suppl. 2), 121-132.

Álvarez-Filip, L., Côté, I. M., Gill, J. A., Watkinson, A. R., \& Dulvy, N. K. (2011). Region-wide temporal and spatial variation in Caribbean reef architecture: is coral cover the whole story? Global Change Biology, 17, 2470-2477.

Aronson, R. B., \& Precht, W. F. (1995). Landscape patterns of reef coral diversity: A test of the intermediate disturbance hypothesis. Journal of Experimental Marine Biology and Ecology, 192, 1-14.

Arroyo-Mora, D. (2008). Características poblacionales del cambute, Strombus galeatus (Gastropoda: Strombidae) en el Parque Marino Ballena, Pacífico, Costa Rica (1999-2003). Revista de Biología Tropical, 56 (Supl. 4), 113-124.

Bakus, G. J. (2007). Quantitative Analysis of Marine Biological Communities: Field Biology and Environment. New Jersey: Wiley-Interscience.

Benfield, S., Baxter, L., Guzman, H. M., \& Mair, J. M. (2008). A comparison of coral reef and coral community fish assemblages in Pacific Panama and environmental factors governing their structure. Journal of the Marine Biological Association of the UK, 88, 1331-1341.

Bezy, M. B., Jiménez, C., Cortés, J., Segura, A., León, A., Alvarado, J. J., Gillén, C., \& Mejía, E. (2006). Contrasting Psammocora-dominated coral communities in Costa Rica, tropical eastern Pacific. Proceeding of $10^{\text {th }}$ International Coral Reef Symposium, Okinawa, 376-381.

Bussing, W., \& López, M. (1996). Fishes collected during the Victor Hensen Costa Rica expedition (1993/1994). Revista de Biología Tropical, 44 (Supl. 3), 183-186.

Campos, J. (1989). Evaluación de la pesca artesanal del Golfo Dulce (Informe Final de Proyecto). Costa Rica: CIMAR, Universidad de Costa Rica.

Clarke, K. R., \& Warwick, R. M. (2001). A further biodiversity index applicable to species lists: variation in taxonomic distinctness. Marine Ecology Progress Series, 216, 265-278.

Clarke, K. R., \& Gorley, R. N. (2006). PRIMER v6: User manual. Plymouth, U.K.: PRIMER-E Ltd.

Cooper, T. F., Gilmour, J. P., \& Fabricius, K. E. (2009). Bioindicators of changes in water quality on coral reefs: review and recommendations for monitoring programmes. Coral Reefs, 28, 589-606.

CoopeSoliDar. (2012). Estudio Regional sobre las Dimensiones Sociales en el Manejo de Áreas Marinas Protegidas: Casos en Costa Rica, Nicaragua, Honduras y Panamá. San José, Costa Rica: International Collective in Support of Fishworkers.

Cortés, J., \& Murillo, M. M. (1985). Comunidades coralinas y arrecifes del Pacífico de Costa Rica. Revista de Biología Tropical, 33, 197-202.

Cortés, J. (1990). The coral reefs of Golfo Dulce, Costa Rica: distribution and community structure. Atoll Research Bulletin, 344, 1-37.

Cortés, J. (1991). Los arrecifes coralinos del Golfo Dulce, Costa Rica: Aspectos Geológicos. Revista Geológica de América Central, 13, 15-24.

Cortés, J. (1992). Los arrecifes coralinos del Golfo Dulce, Costa Rica: aspectos ecológicos. Revista de Biología Tropical, 40, 19-26.

Cortés, J., \& Jiménez, C. E. (1996). Coastal-marine environments of Parque Nacional Corcovado, Puntarenas, Costa Rica. Revista de Biología Tropical, 44 (Suppl. 3), 35-40.

Cortés, J., \& Guzmán, H. M. (1998). Organismos de los arrecifes coralinos de Costa Rica: Descripción, distribución geográfica e historia natural de los corales zooxantelados (Anthozoa: Scleractinia) del Pacífico. Revista de Biología Tropical, 46, 55-92. 
Cortés, J. (Ed.). (2003). Latin American Coral Reefs. Amsterdam: Elsevier Science B.V.

Cortés, J., \& Jiménez, C. E. (2003). Corals and coral reefs of the Pacific of Costa Rica: history, research and status. In J. Cortés (Ed.), Latin American Coral Reefs (pp. 361-385). Amsterdam: Elsevier Science B.V.

Cortés, J., Guzmán, H. M., Fonseca, A.C., Alvarado, J.J., Breedy, O., Fernández, C., Segura, A., \& Ruiz, E. (2009). Ambientes y organismos marinos de la Reserva Biológica Isla del Caño, Área de Conservación Osa, Costa Rica (Serie Técnica: Apoyando los esfuerzos en el manejo y protección de la biodiversidad tropical. No. 13) San José, Costa Rica: The Nature Conservancy.

Cortés, J., Jiménez, C. E., Fonseca, A. C., \& Alvarado, J. J. (2010). Status and conservation of coral reefs in Costa Rica. Revista de Biología Tropical, 58 (Suppl. 1), 33-50.

Dominici-Arosemena, A., Brugnoli-Olivera, E., CortésNúñez, J., Molina-Ureña, H., \& Quesada-Alpízar, M. (2005). Community structure of eastern Pacific reef fishes (Gulf of Papagayo, Costa Rica). Tecnociencia, 7, 19-41.

Dominici-Arosemena, A., \& Wolff, M. (2006). Reef fish community structure in the Eastern Tropical Pacific (Panama): living on a relative stable rocky environment. Helgoland Marine Research, 60, 287-305.

Edgar, G. J., Banks, S., Farinha, J .M., Calvopinha, M., \& Martínez, M. (2004). Regional biogeography of shallow reef fish and macroinvertebrate communities in the Galapagos archipelago. Journal of Biogeography, 31, 1107-1124.

Espinoza, M., \& Salas, E. (2005). Estructura de las comunidades de peces de arrecife en las Islas Catalinas y Playa Ocotal, Pacífico Norte de Costa Rica. Revista de Biología Tropical, 53, 523-536.

Fonseca, A. C., Dean, H. K., \& J. Cortés. (2006). Noncolonial coral macroborers as indicators of coral reef stress in the south Pacific of Costa Rica. Revista de Biología Tropical, 54, 101-115.

Friedlander, A. M., \& DeMartini, E. E. (2002). Contrasts in density, size, and biomass of reef fishes between the northwestern and the main Hawaiian Islands: the effects of fishing down apex predators. Marine Ecology Progress Series, 230, 253-264.

Friedlander, A., Zgliczynski, B., Ballesteros, E., AburtoOropeza, O., Bolaños, A., \& Sala, E. (2012). The shallow-water fish assemblage of Isla del Coco National Park, Costa Rica: structure and patterns in an isolated, predator-dominated ecosystem. Revista de Biología Tropical, 60 (Suppl. 3), 321-338.

Giorgi, F. (2006). Climate change hot-spots. Geophysical Research Letters, 33, L08707.
Glynn, P. W., Druffel, E. M., \& Dunbar, R. B. (1983). A dead Central American coral reef tract: possible link with the Little Ice Age. Journal of Marine Research, 41, 605-637.

Guzmán, H. M., Cortés, J., Richmond, R. H., \& Glynn, P. W. (1987). Efectos del fenómeno de "El NiñoOscilación Sureña" 1982-83 en los arrecifes coralinos de la Isla del Caño, Costa Rica. Revista de Biología Tropical, 35, 325-332.

Guzmán, H. M., \& Cortés, J. (1989). Coral reef community structure at Caño Island, Pacific Costa Rica. P.S.Z.N.I: Marine Ecology, 10, 23-41.

Guzmán, H. M. (1998). Distribución y abundancia de organismos coralívoros en los arrecifes coralinos de la Isla del Caño, Costa Rica. Revista Biología Tropical, 36, 191-207.

Guzmán, H. M., \& Cortés, J. (2001). Changes in reef community structure after fifteen years of natural disturbances in the eastern Pacific (Costa Rica). Bulletin of Marine Sciences, 69, 133-149.

Guzmán-Mora, A. (2012). Diagnóstico de la composición de capturas de la pesca artesanal de Golfo Dulce, Pacifico Sur, Costa Rica (Tesis de Maestría). Universidad de Costa Rica, San Pedro, Costa Rica.

Hutchings, P. A. (1986). Biological destruction of coral reefs. A review. Coral Reefs, 4, 239-252.

Jiménez, C. E., \& Cortés, J. (2001). Effects of the 19911992 El Niño on scleractinian corals of the Costa Rican central Pacific coast. Revista de Biología Tropical, 49 (Suppl. 2), 239-250.

Jiménez, C. E., \& Cortés, J. (2003). Coral cover change associated to El Niño, eastern Pacific, Costa Rica, 1992-2001. P.S.Z.N.: Marine Ecology, 24, 179-192.

Kremen, C., Merenlender A. D., \& Murphy D. D. (1994). Ecological monitoring: a vital need for integrated conservation and development programs in the tropics. Conservation Biology, 8, 388-397.

Lee, S. C. (2006). Habitat complexity and consumermediated positive feedbacks on a Caribbean coral reef. Oikos, 112, 442-447.

Manzello, D. P. (2010a). Ocean acidification hot spots: Spatiotemporal dynamics of the seawater $\mathrm{CO}_{2}$ system of eastern Pacific coral reefs. Limnology and Oceanography, 55, 239-248.

Manzello, D. P. (2010b). Coral growth with thermal stress and ocean acidification: lessons from the eastern tropical Pacific. Coral Reefs, 29, 749-758.

McCook, L. J., Jompa, J., \& Díaz-Pulido, G. (2001). Competition between corals and algae on coral reefs: a review of evidence and mechanisms. Coral Reefs, 19, 400-417.

Neelin, J. D., Münnich, M., Su, H., Meyerson, J. E., \& Holloway, C. E. (2006). Tropical drying trends in 
global warming models and observations. Proceedings of the National Academy of Sciences, 103, 6110-6115.

Obando-Acuña, V. (2002). Biodiversidad en Costa Rica: estado del conocimiento y gestión. Heredia, Costa Rica: Instituto Nacional de Biodiversidad.

Quesada-Alpízar, M. A., \& Cortés, J. (2006). Los ecosistemas marinos del Pacífico Sur de Costa Rica: estado del conocimiento y perspectivas de manejo. Revista de Biología Tropical, 54, 101-145.

Quesada-Alpízar, M. A., Cortés, J., Alvarado, J. J., \& Fonseca, A. C. (2006). Características hidrográficas y biológicas de la zona marino-costera del área de conservación OSA. Serie Técnica: Apoyando los esfuerzos en manejo y protección de la biodiversidad tropical. San José, Costa Rica: The Nature Conservancy.

Rogers, C. S., Garrison, G., Grober, R., Hillis, Z. M., \& Franke, M.A. (1994). Manual para el monitoreo de arrecifes de coral en el Caribe y el Atlántico occidental. Islas Vírgenes: The Nature Conservancy, World Wild Fund.

Rojas-Figueroa, R. (2001). Caracterización de la ictiofauna de los sustratos duros de la parte interna del Golfo Dulce, Costa Rica (Tesis de Licenciatura) Universidad de Costa Rica, San Pedro, Costa Rica.

Salas, E., \& Alvarado, J. J. (2008). Lista de peces costeros del Parque Nacional Marino Ballena, Costa Rica, con anotaciones sobre su ecología. Brenesia, 69, 43-64.

Salas, E., Ross-Salazar, E., \& Arias, A. (2012). Diagnóstico de áreas marinas protegidas y áreas marinas para la pesca responsable en el Pacífico costarricense. San José, Costa Rica: Fundación MarViva.
Salas, E., Sánchez-Godínez, C., \& Montero-Cordero, A. (2015). Peces marinos de la Reserva Biológica Isla del Caño: Estructura de las comunidades y lista actualizada. Revista de Biología Tropical, 63 (Suplemento 1): 97-116.

Sammarco, P. W. (1980). Diadema and its relationship to coral spat mortality: grazing, competition and biological disturbance. Journal of Experimental Marine Biology and Ecology, 45, 245-472.

Sammarco, P. W. (1982). Echinoid grazing as a structure force in coral communities: whole reef manipulations Journal of Experimental Marine Biology and Ecology, 61, 31-55.

Spurgeon, J. P. (1992). The economic valuation of coral reefs. Marine Pollution Bulletin, 24, 529-536.

Velarde, D. (2004). Monitoreo de Biodiversidad. Instituto Nacional de Recursos Naturales, Lima, Perú.

Wehrtmann, I. S., \& Cortés, J. (Eds.). (2009). Marine Biodiversity of Costa Rica, Central America. Berlin: Monographiae Biologicae, Springer+Business Media B.V.

Weinberg, S. (1981). A comparison of coral reef survey methods. Bijdragen tot de Dierkunde, 51, 199-218.

Wolff, M. (1996). Demersal fish assemblages along the Pacific coast of Costa Rica: a quatitative and multivariate assessment based on the Victor Hensen Costa Rica Expedition (1993/1994). Revista de Biología Tropical, 44 (Suppl. 1), 187-214.

Yoccoz, N. G., Nichols, J. D., \& Boulinier, T. (2001). Monitoring of biological diversity in space and time. Trends on Ecology and Evolution, 16, 446-453. 


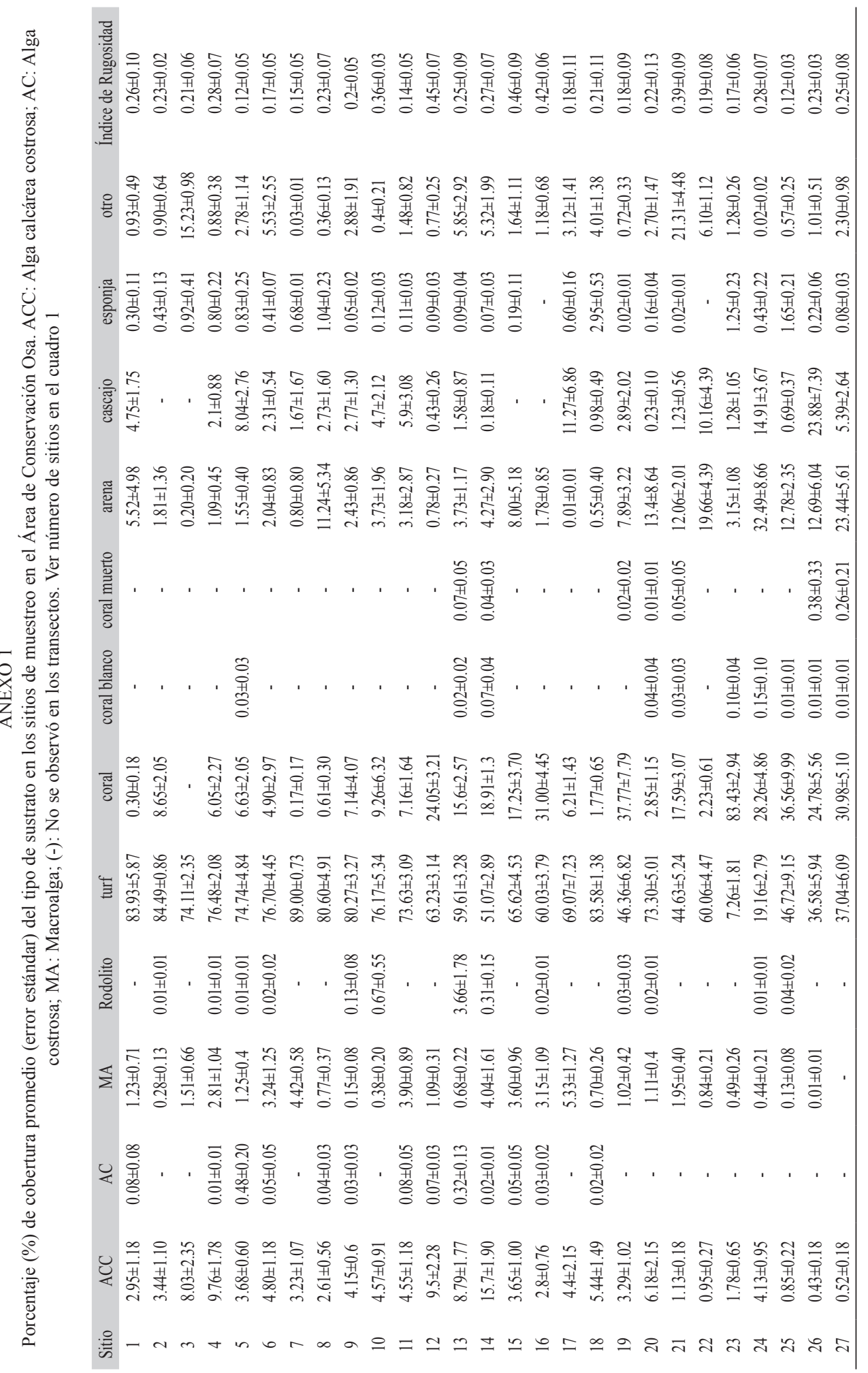




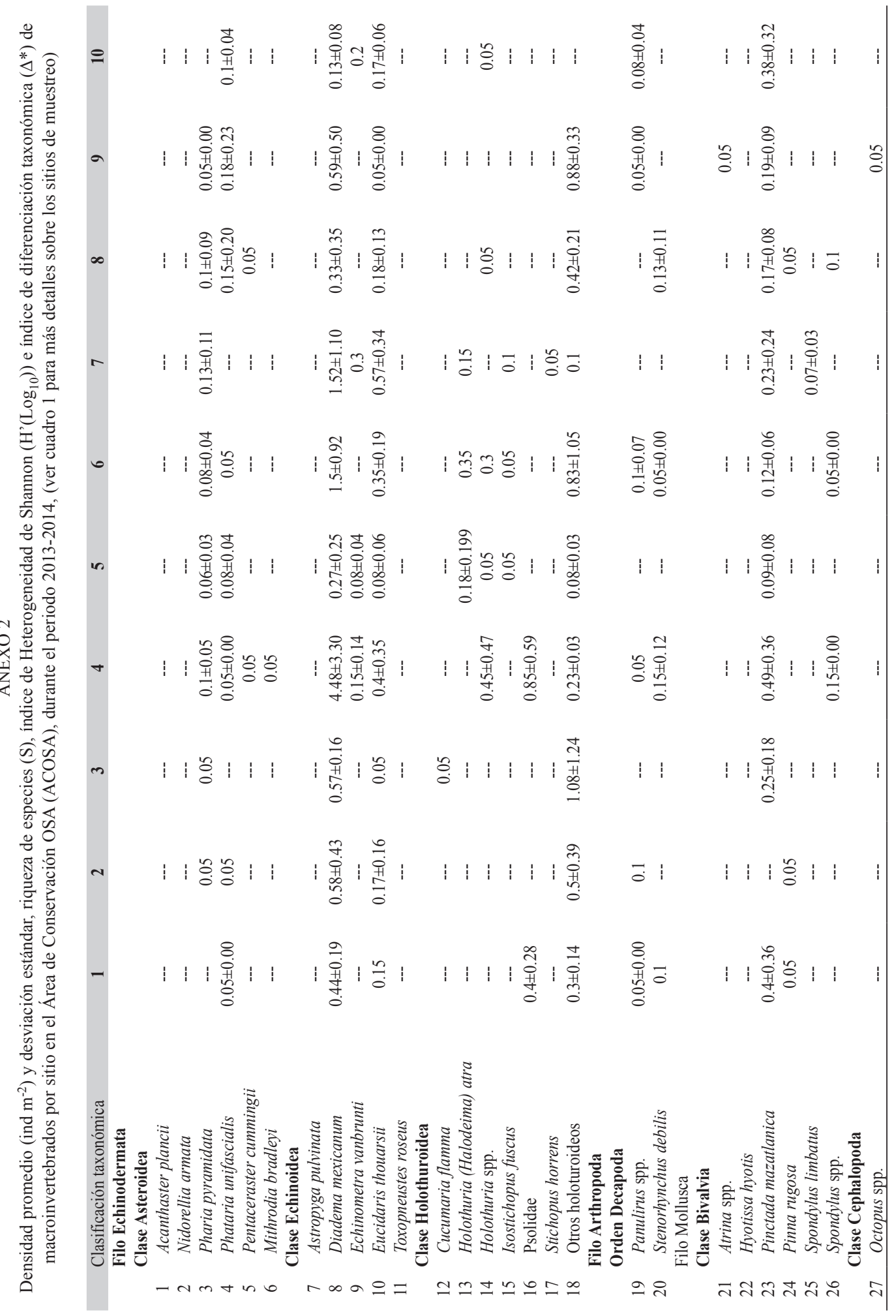




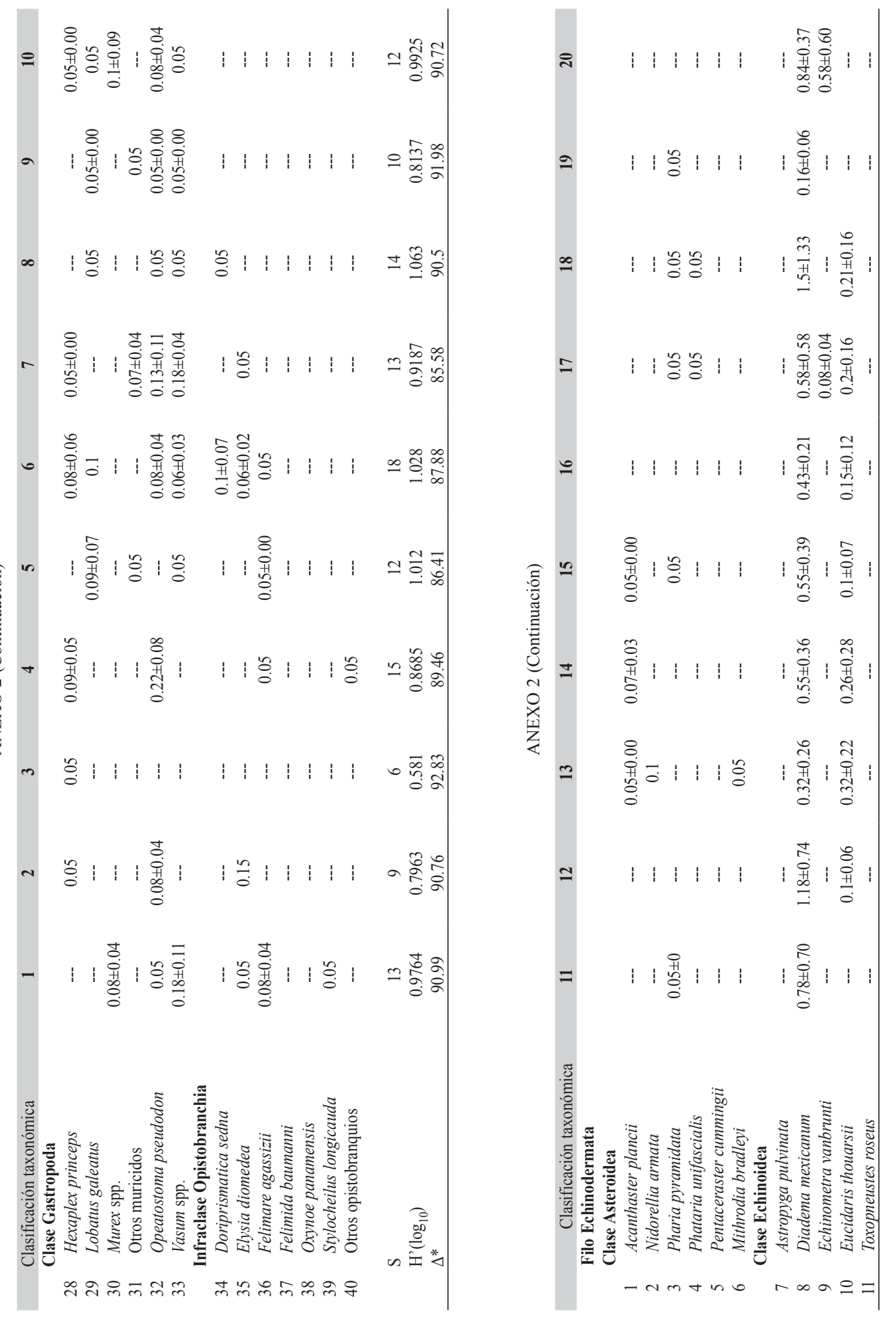




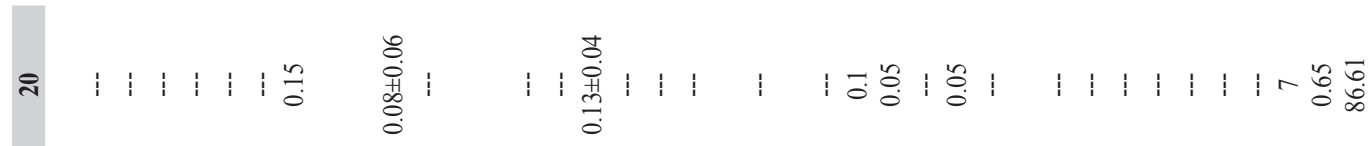

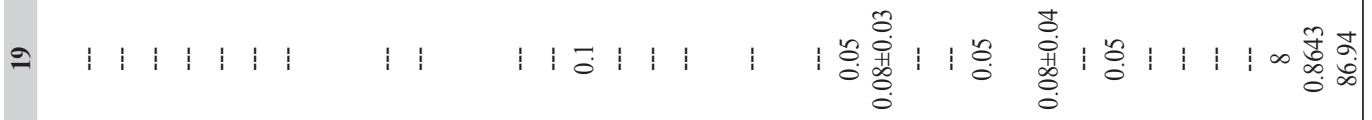

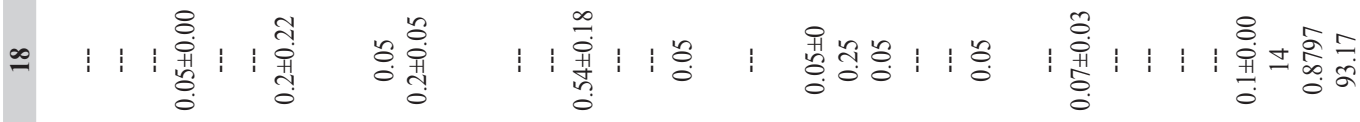

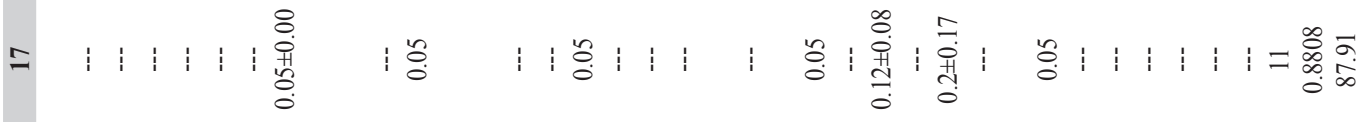

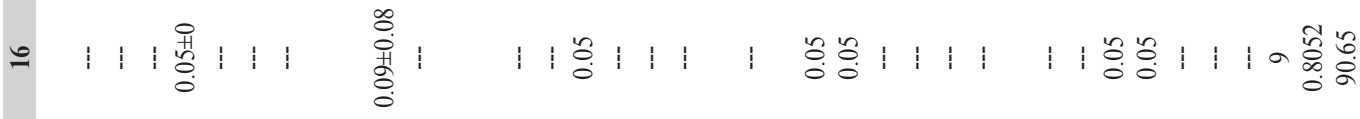
在

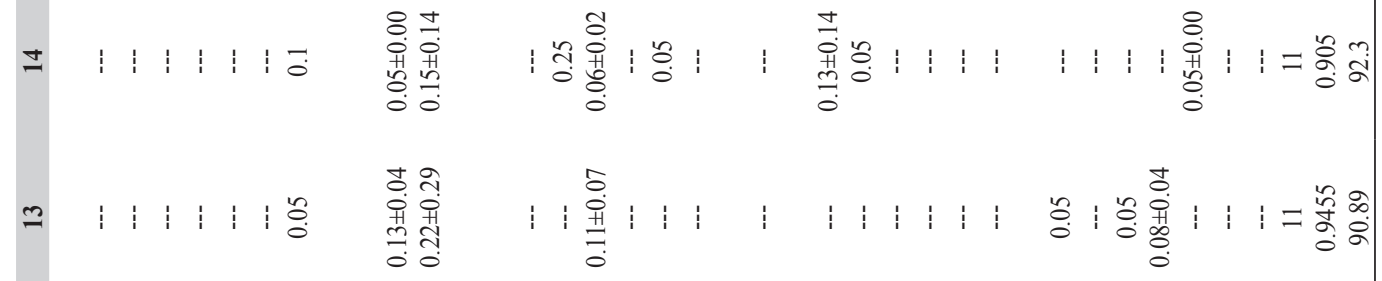

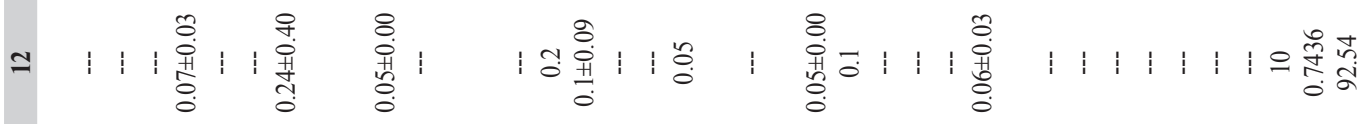

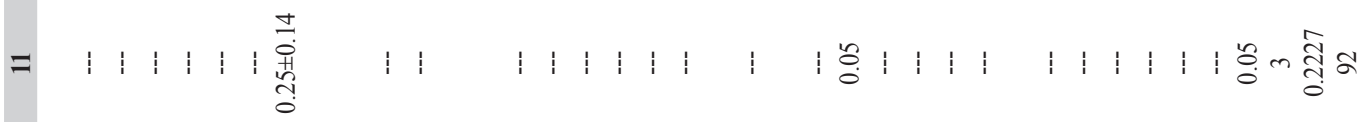

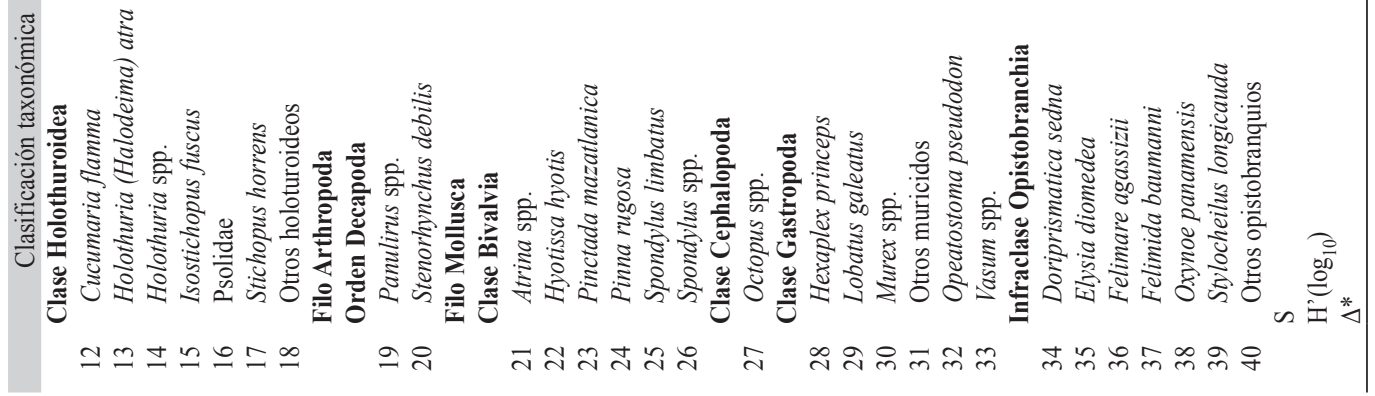


ANEXO 2 (Continuación)

\begin{tabular}{|c|c|c|c|c|c|c|c|c|}
\hline & Clasificación taxonómica & 21 & 22 & 23 & 24 & 25 & 26 & 27 \\
\hline \multicolumn{9}{|c|}{ Filo Echinodermata } \\
\hline \multicolumn{9}{|c|}{ Clase Asteroidea } \\
\hline 1 & Acanthaster plancii & --- & --- & --- & --- & --- & --- & --- \\
\hline 2 & Nidorellia armata & --- & --- & --- & --- & --- & --- & --- \\
\hline 3 & Pharia pyramidata & --- & --- & 0.05 & --- & --- & --- & --- \\
\hline 4 & Phataria unifascialis & --- & --- & --- & --- & 0.05 & --- & --- \\
\hline 5 & Pentaceraster cummingii & --- & --- & --- & --- & --- & --- & --- \\
\hline 6 & Mithrodia bradleyi & --- & --- & --- & --- & --- & --- & --- \\
\hline \multicolumn{9}{|c|}{ Clase Echinoidea } \\
\hline 7 & Astropyga pulvinata & --- & --- & --- & --- & 0.05 & --- & --- \\
\hline 8 & Diadema mexicanum & --- & 0.1 & --- & $0.25 \pm 0.17$ & --- & 0.1 & $0.05 \pm 0.00$ \\
\hline 9 & Echinometra vanbrunti & --- & --- & 0.05 & --- & --- & --- & --- \\
\hline 10 & Eucidaris thouarsii & $0.1 \pm 0.07$ & 0.05 & $0.05 \pm 0.00$ & $0.05 \pm 0.00$ & --- & $0.07 \pm 0.03$ & 0.05 \\
\hline 11 & Toxopneustes roseus & --- & --- & --- & $0.05 \pm 0.00$ & --- & --- & --- \\
\hline \multicolumn{9}{|c|}{ Clase Holothuroidea } \\
\hline 12 & Cucumaria flamma & --- & --- & --- & --- & --- & --- & --- \\
\hline 13 & Holothuria (Halodeima) atra & --- & --- & --- & --- & --- & 0.05 & 0.05 \\
\hline 14 & Holothuria spp. & --- & --- & 0.05 & 0.05 & --- & $0.22 \pm 0.25$ & $0.21 \pm 0.26$ \\
\hline 15 & Isostichopus fuscus & --- & --- & --- & 0.05 & --- & --- & --- \\
\hline 16 & Psolidae & --- & --- & --- & --- & --- & --- & --- \\
\hline 17 & Stichopus horrens & -- & --- & --- & --- & --- & --- & --- \\
\hline 18 & Otros holoturoideos & 0.3 & 0.05 & $2.48 \pm 2.41$ & $3.23 \pm 3.58$ & --- & $0.08 \pm 0.04$ & $0.05 \pm 0.00$ \\
\hline \multicolumn{9}{|c|}{ Filo Arthropoda } \\
\hline \multicolumn{9}{|c|}{ Orden Decapoda } \\
\hline 19 & Panulirus spp. & --- & --- & 0.05 & --- & --- & --- & --- \\
\hline 20 & Stenorhynchus debilis & --- & --- & 0.05 & --- & 0.05 & $0.08 \pm 0.04$ & $0.08 \pm 0.03$ \\
\hline \multicolumn{9}{|c|}{ Filo Mollusca } \\
\hline \multicolumn{9}{|c|}{ Clase Bivalvia } \\
\hline 21 & Atrina sp. & --- & --- & --- & --- & --- & --- & --- \\
\hline 22 & Hyotissa hyotis & $0.29 \pm 0.15$ & $0.4 \pm 0.09$ & --- & $0.09 \pm 0.04$ & --- & $0.09 \pm 0.08$ & --- \\
\hline 23 & Pinctada mazatlanica & $0.29 \pm 0.18$ & $0.20 \pm 0.14$ & 0.05 & 0.05 & --- & $0.17 \pm 0.15$ & $0.08 \pm 0.04$ \\
\hline 24 & Pinna rugosa & $0.05 \pm 0.00$ & --- & --- & --- & --- & --- & --- \\
\hline 25 & Spondylus limbatus & --- & --- & --- & 0.05 & --- & --- & --- \\
\hline 26 & Spondylus spp. & $0.14 \pm 0.07$ & $0.34 \pm 0.27$ & 0.05 & $0.05 \pm 0.00$ & --- & $0.31 \pm 0.26$ & $0.1 \pm 0.07$ \\
\hline \multicolumn{9}{|c|}{ Clase Cephalopoda } \\
\hline 27 & Octopus spp. & --- & --- & --- & --- & --- & --- & --- \\
\hline \multicolumn{9}{|c|}{ Clase Gastropoda } \\
\hline 28 & Hexaplex princeps & $0.17 \pm 0.06$ & $0.09 \pm 0.05$ & 0.05 & --- & 0.05 & 0.05 & --- \\
\hline 29 & Lobatus galeatus & --- & $0.1 \pm 0.00$ & $0.1 \pm 0.07$ & $0.05 \pm 0.00$ & --- & --- & --- \\
\hline 30 & Murex spp. & 0.05 & $0.12 \pm 0.06$ & --- & --- & --- & 0.05 & --- \\
\hline 31 & Otros muricidos & --- & 0.05 & --- & --- & --- & --- & --- \\
\hline 32 & Opeatostoma pseudodon & -- & --- & --- & --- & --- & --- & --- \\
\hline 33 & Vasum spp. & --- & --- & --- & --- & 0.1 & --- & --- \\
\hline \multicolumn{9}{|c|}{ Infraclase Opistobranchia } \\
\hline 34 & Doriprismatica sedna & --- & --- & --- & --- & 0.05 & --- & --- \\
\hline 35 & Elysia diomedea & --- & --- & $0.05 \pm 0.00$ & $0.18 \pm 0.09$ & $0.12 \pm 0.08$ & --- & --- \\
\hline 36 & Felimare agassizii & --- & --- & $0.08 \pm 0.04$ & $0.05 \pm 0.00$ & $0.06 \pm 0.03$ & --- & --- \\
\hline 37 & Felimida baumanni & --- & --- & --- & --- & 0.05 & --- & --- \\
\hline 38 & Oxynoe panamensis & --- & --- & --- & --- & --- & --- & --- \\
\hline 39 & Stylocheilus longicauda & --- & --- & --- & --- & --- & --- & --- \\
\hline 40 & Otros opistobranquios & --- & --- & --- & --- & --- & --- & --- \\
\hline & $\mathrm{S}$ & 7 & 8 & 12 & 12 & 9 & 10 & 7 \\
\hline & $H^{\prime}(\log 10)$ & 0.7731 & 0.822 & 1.067 & 0.9932 & 0.9281 & 0.9168 & 0.7879 \\
\hline & $\Delta^{*}$ & 78.58 & 80.63 & 91 & 89.4 & 80.24 & 89.63 & 89.49 \\
\hline
\end{tabular}




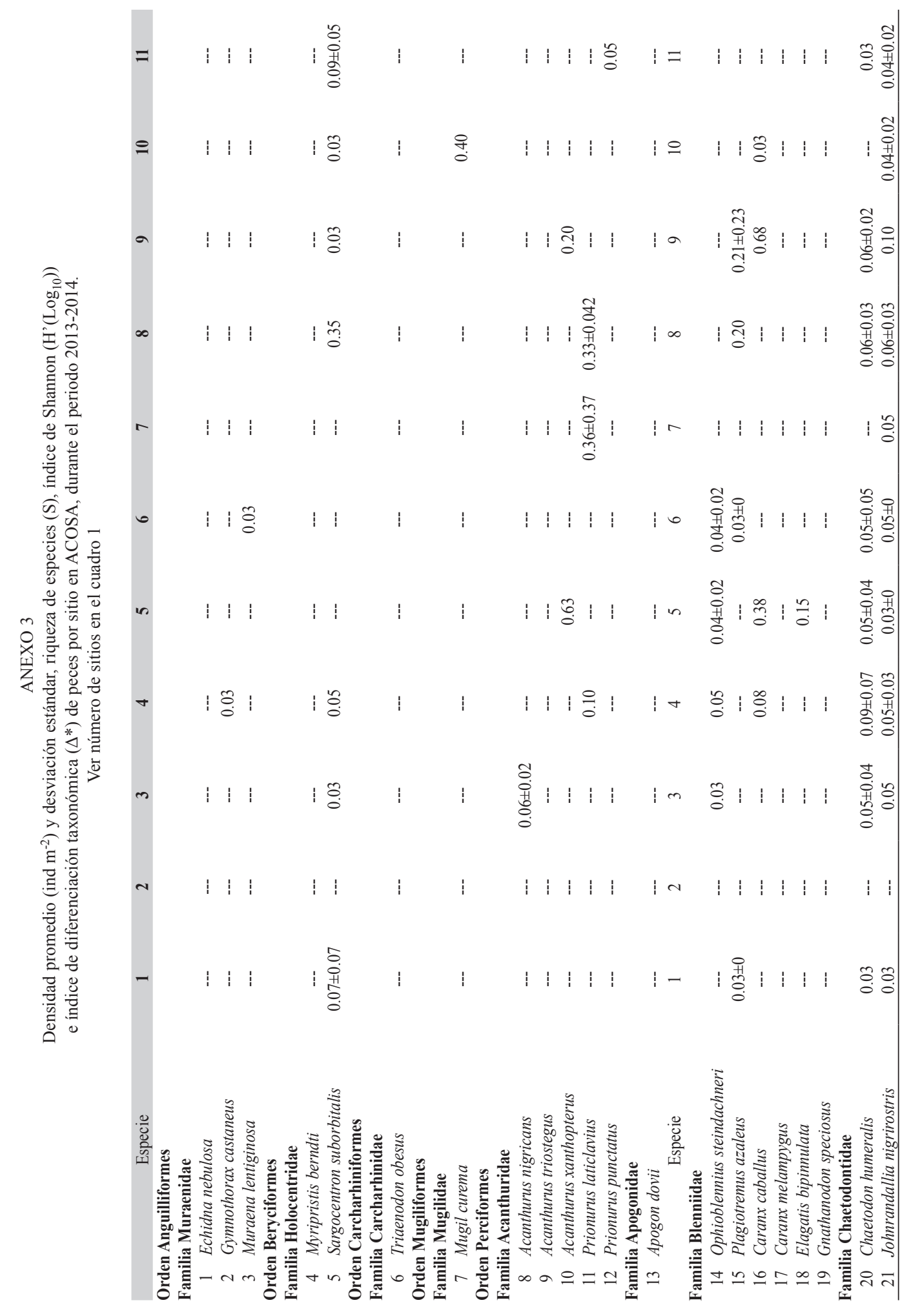




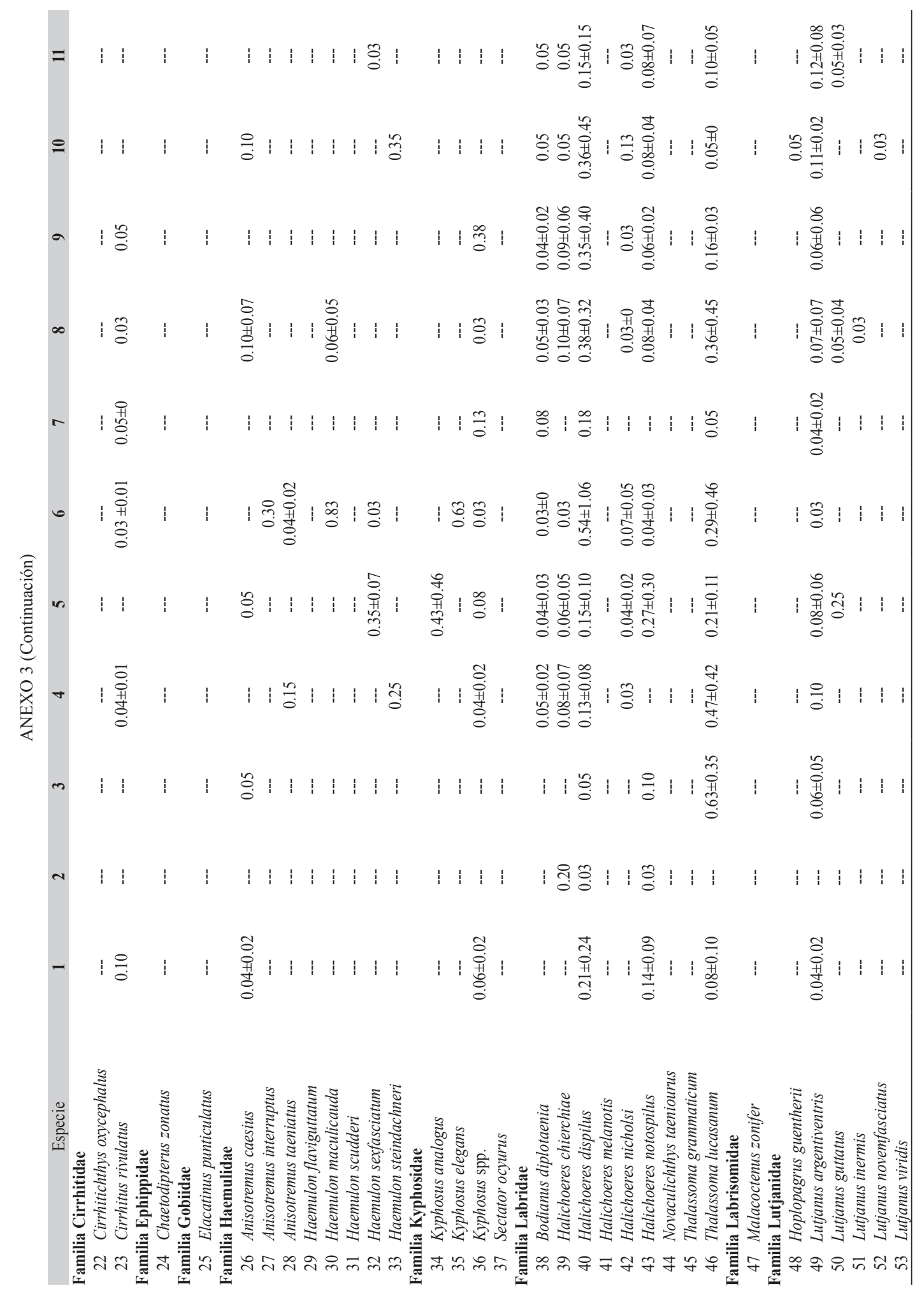




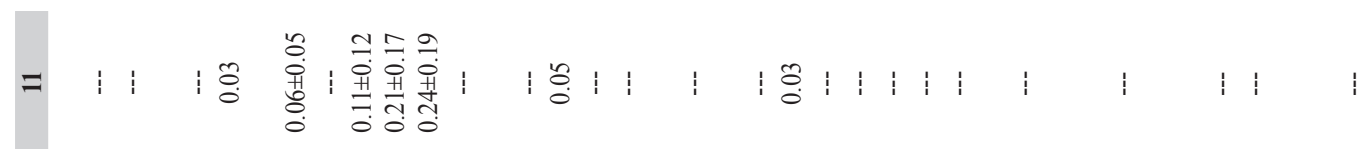

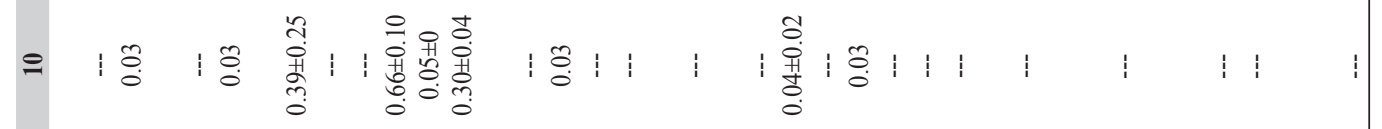

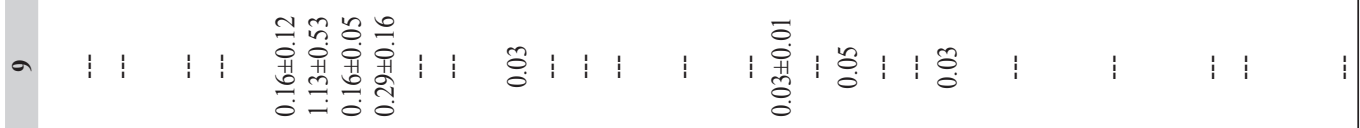

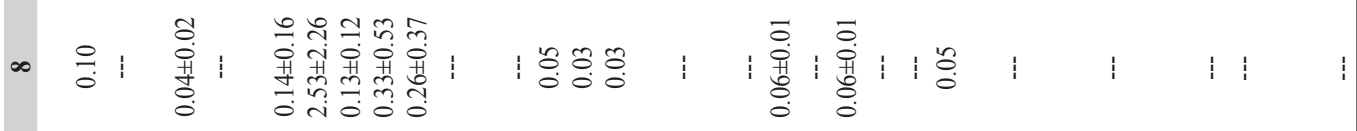

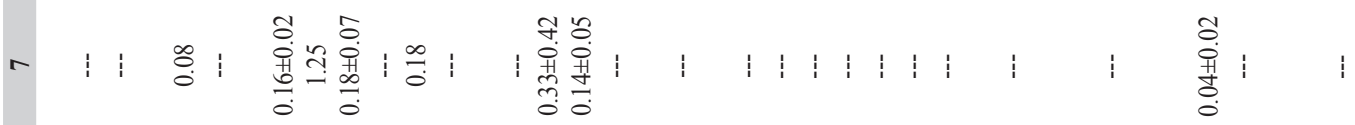

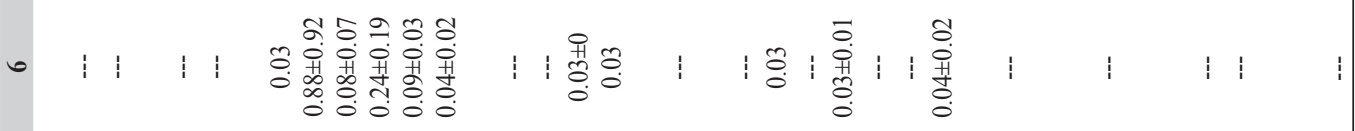

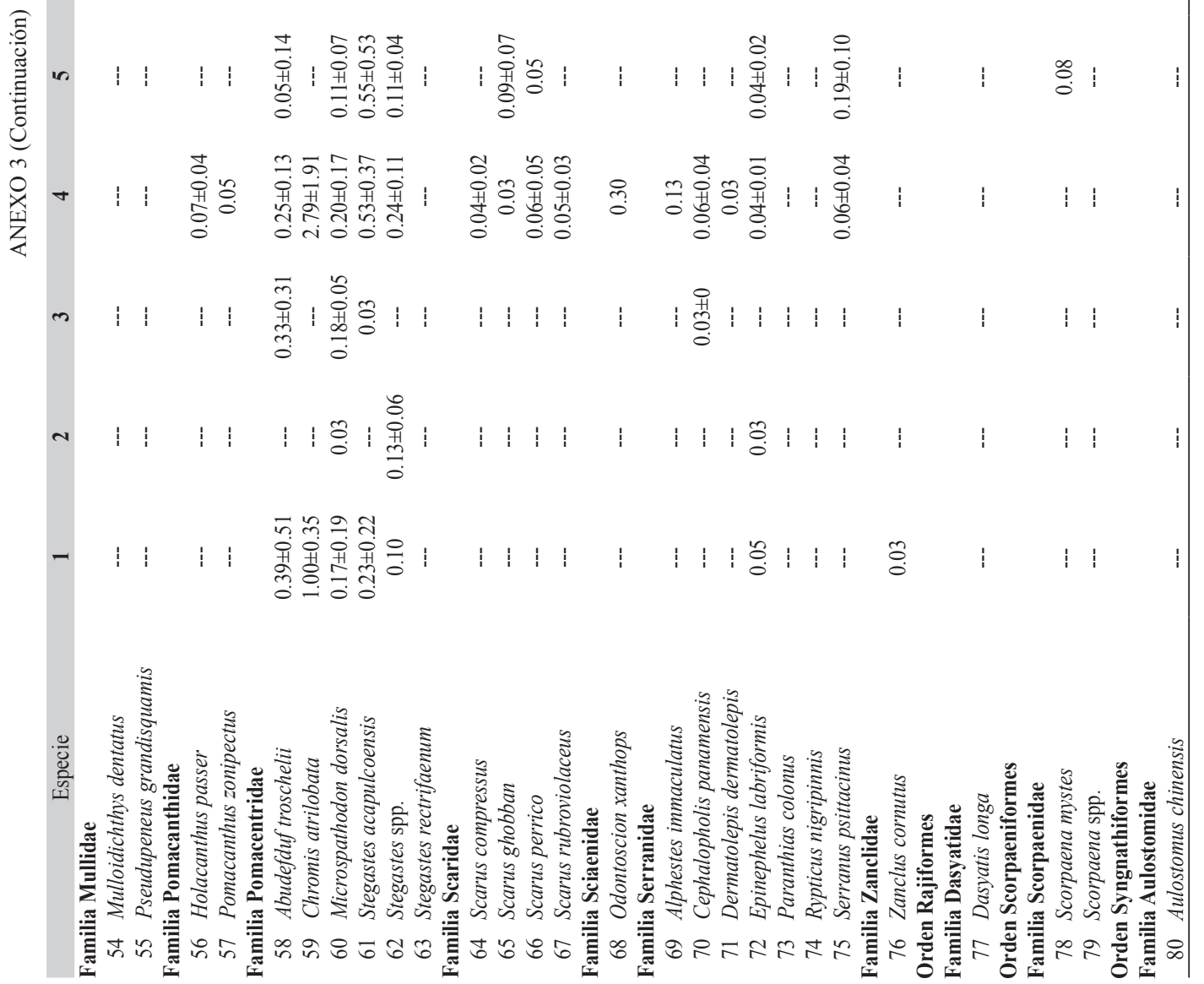




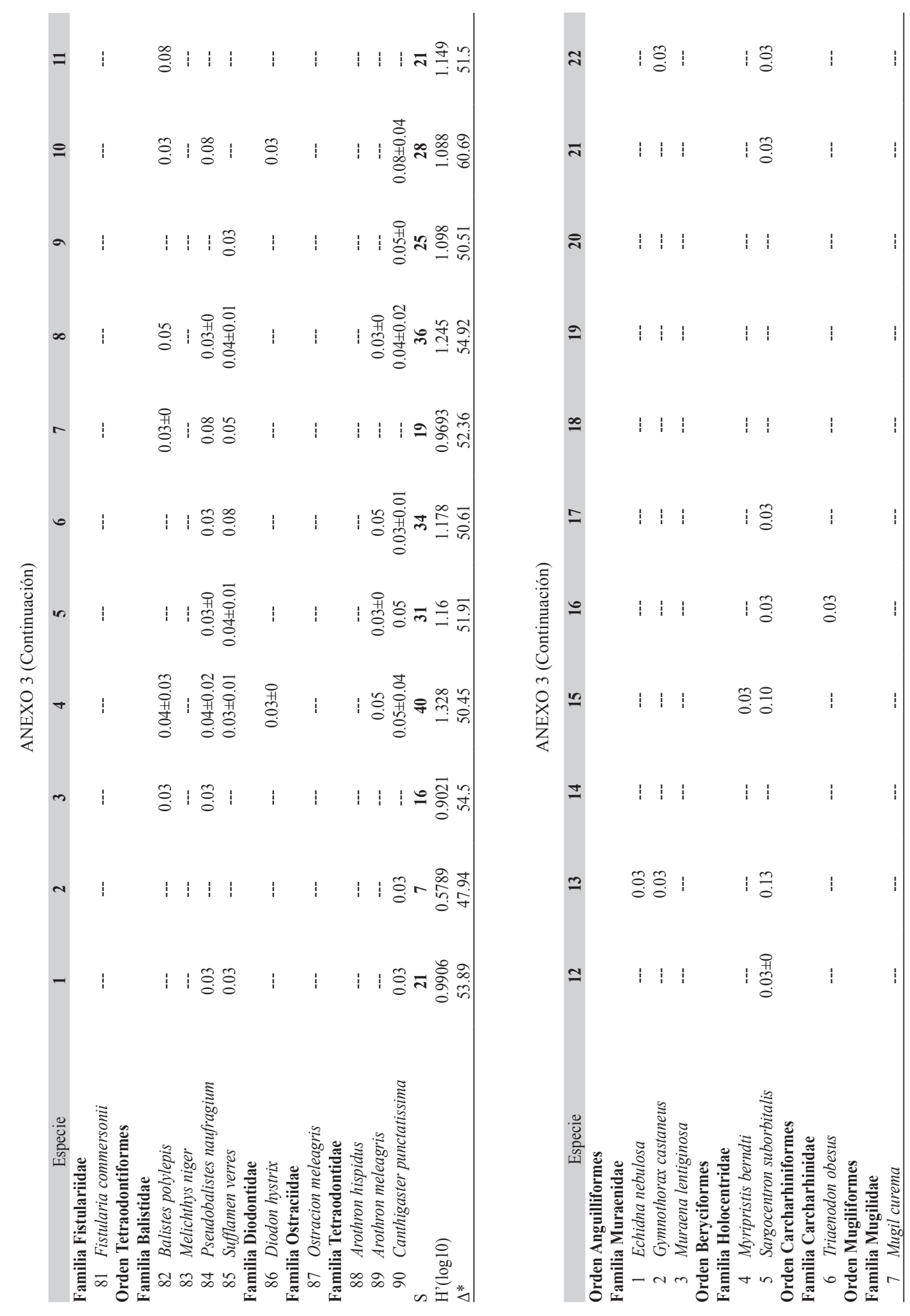




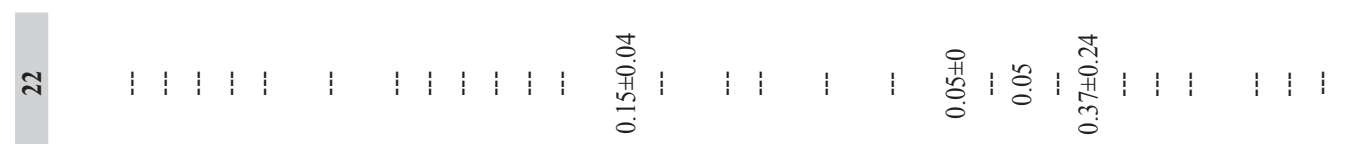

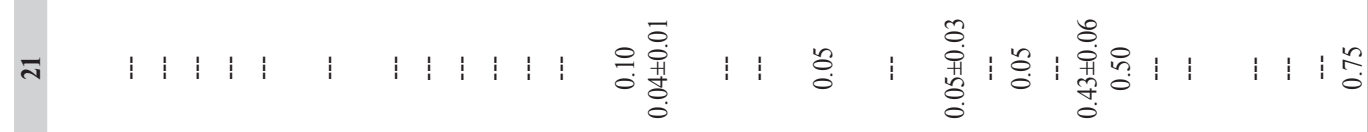
สิ |

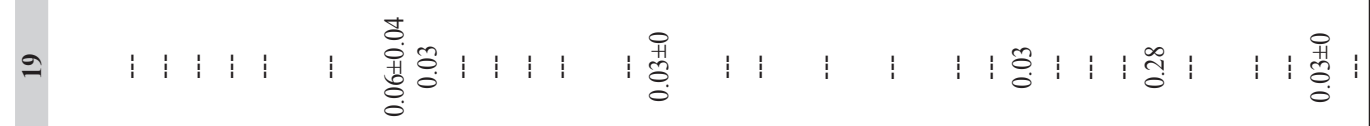

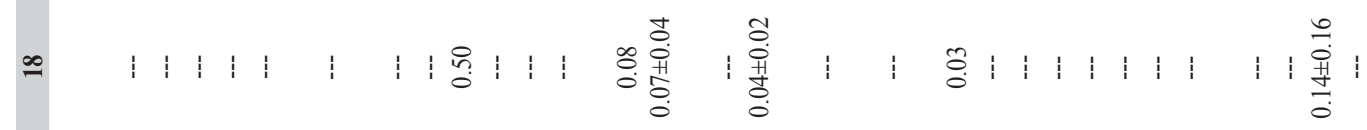

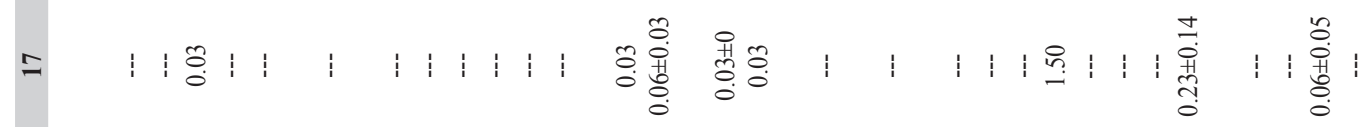

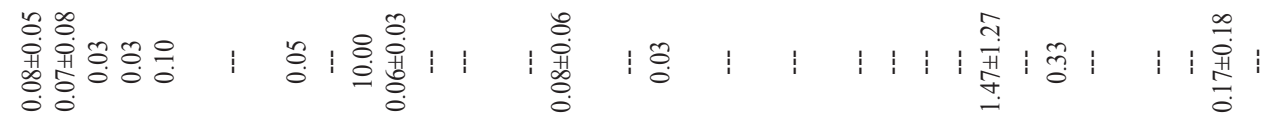

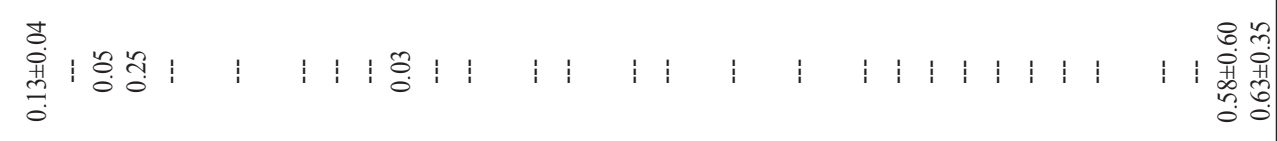

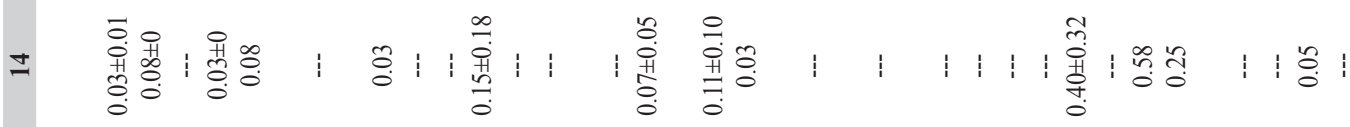

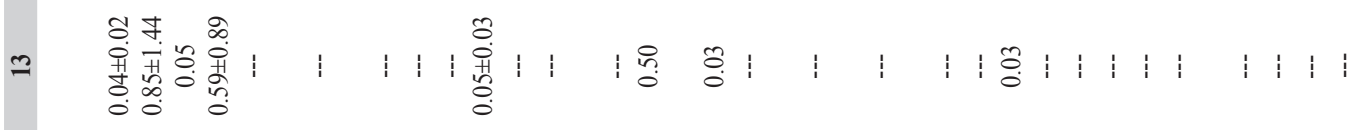

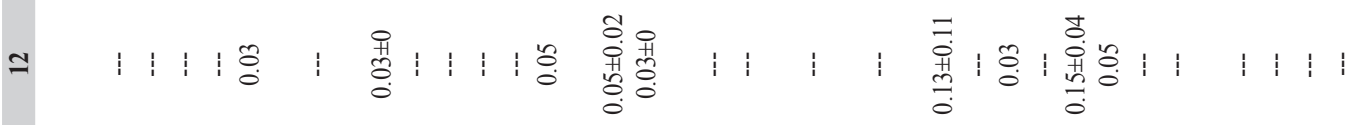

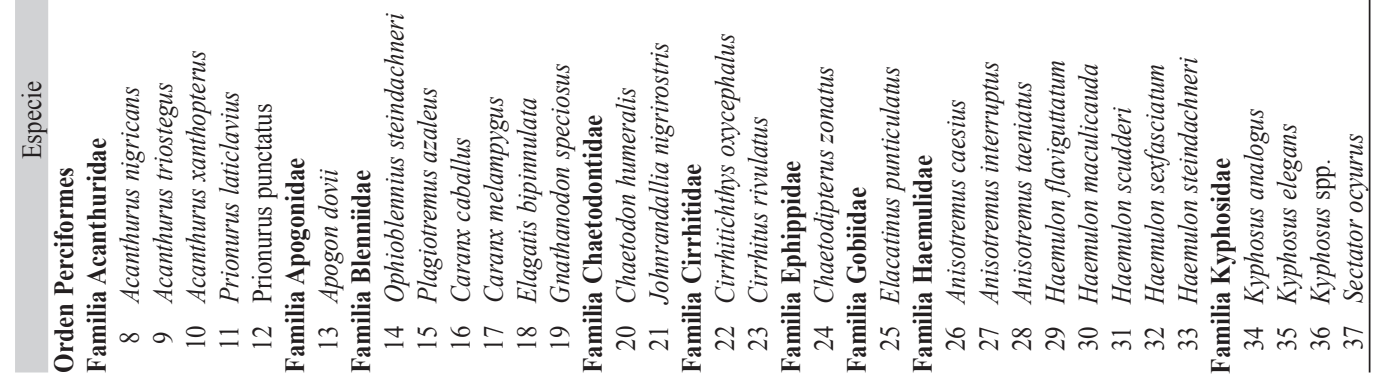




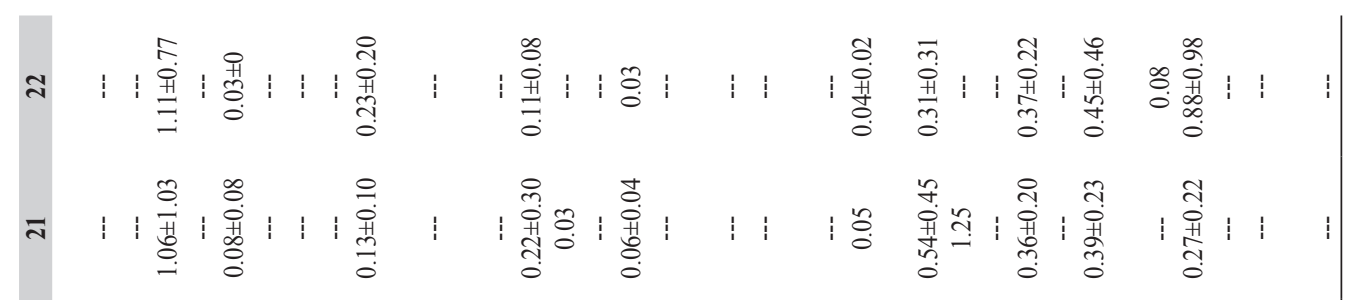

\%

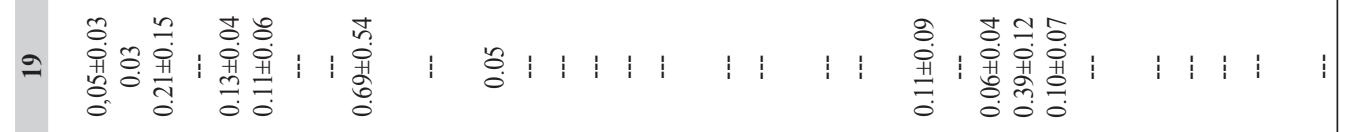

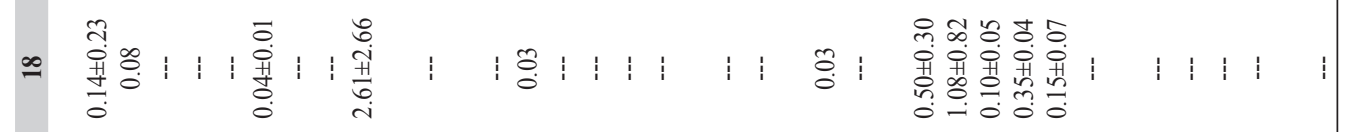

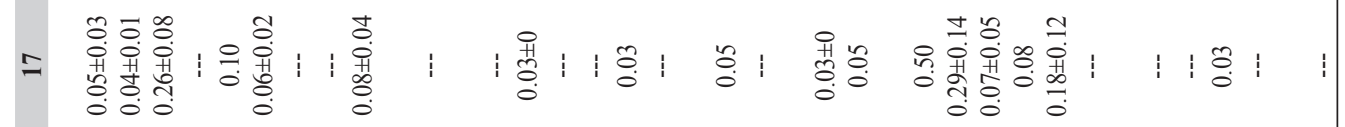

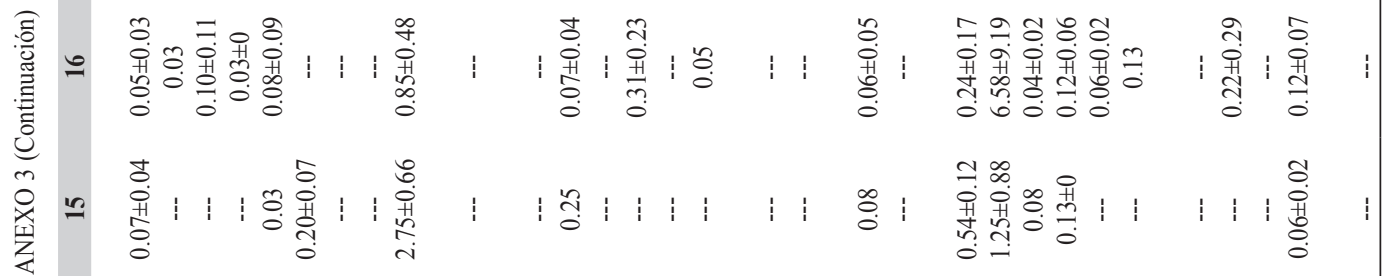

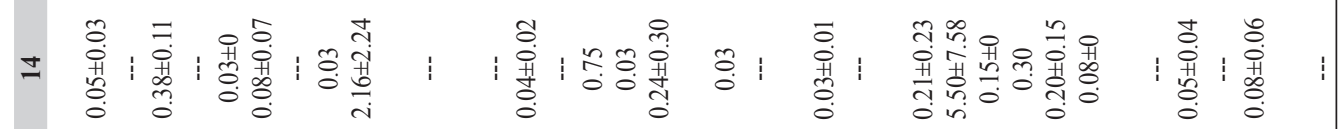

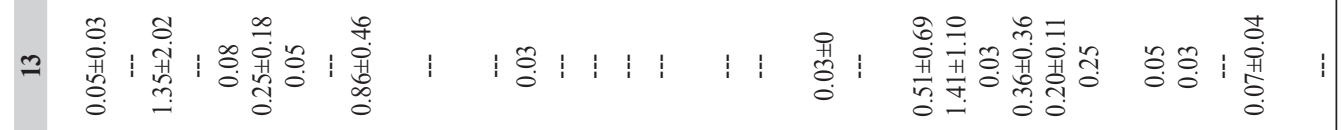

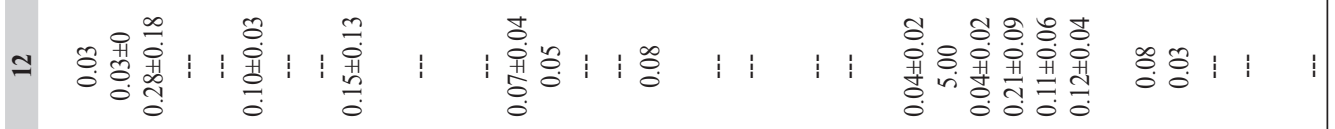

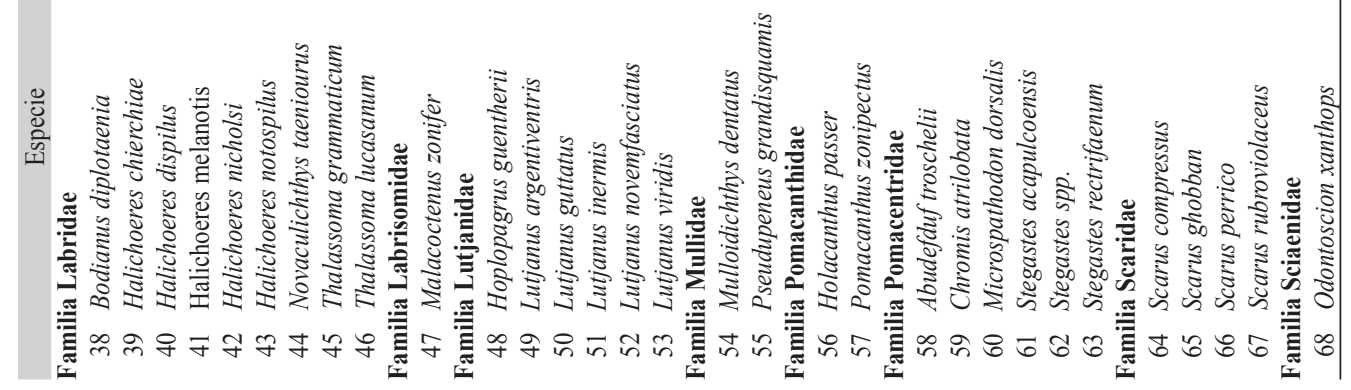


ส

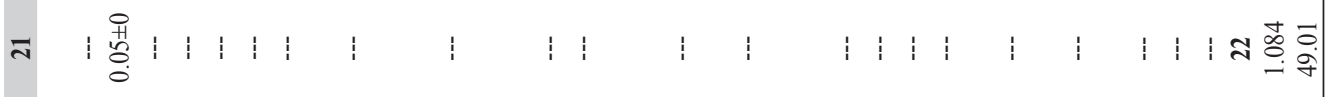

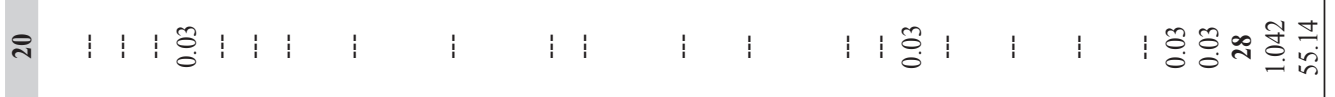

-

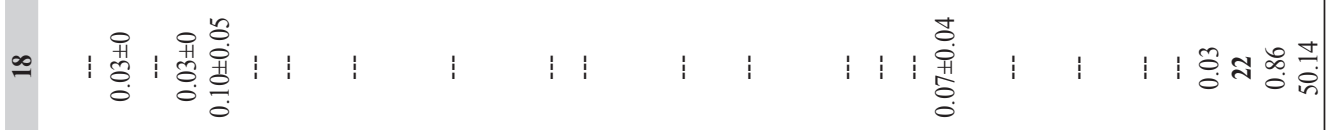

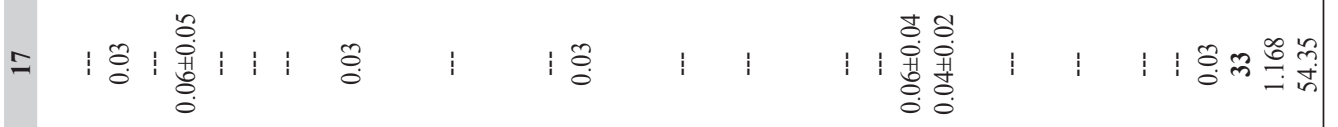

峷口

尊n!

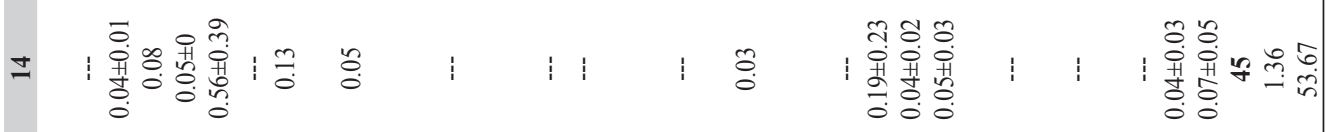

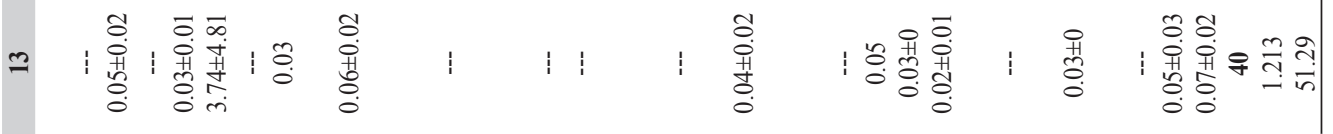

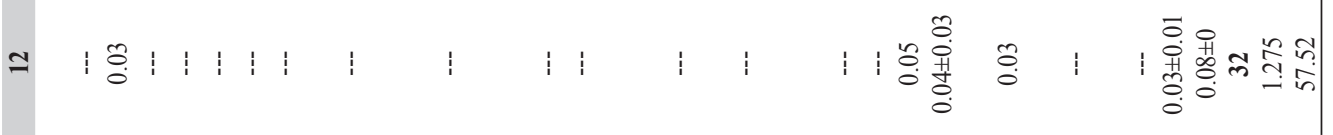

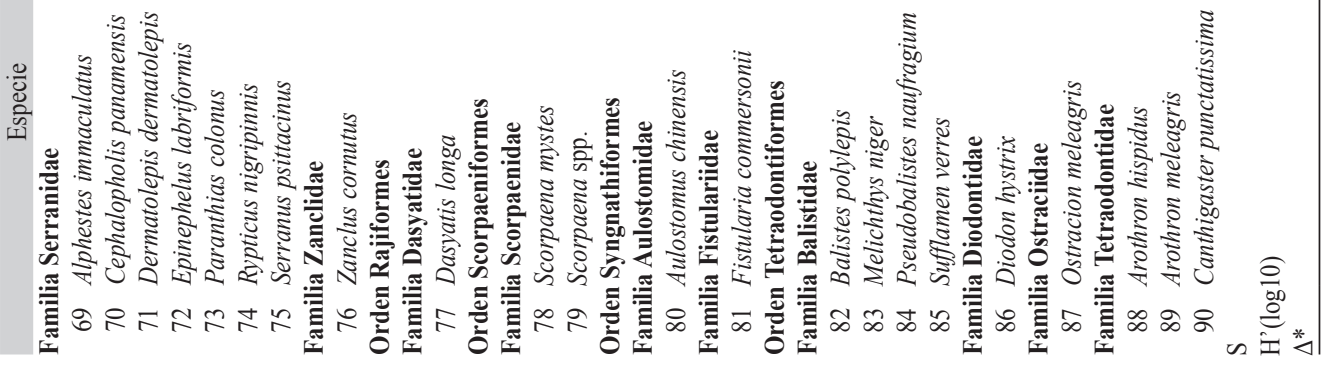


ANEXO 3 (Continuación)

\begin{tabular}{|c|c|c|c|c|c|}
\hline Especie & 23 & 24 & 25 & 26 & 27 \\
\hline \multicolumn{6}{|l|}{ Orden Anguilliformes } \\
\hline \multicolumn{6}{|l|}{ Familia Muraenidae } \\
\hline 1 Echidna nebulosa & --- & --- & --- & --- & --- \\
\hline 2 Gymnothorax castaneus & --- & --- & --- & $0.03 \pm 0$ & --- \\
\hline 3 Muraena lentiginosa & --- & --- & --- & --- & --- \\
\hline \multicolumn{6}{|l|}{ Orden Beryciformes } \\
\hline \multicolumn{6}{|l|}{ Familia Holocentridae } \\
\hline 4 Myripristis berndti & --- & 0.05 & --- & --- & --- \\
\hline 5 Sargocentron suborbitalis & 0.05 & $0.05 \pm 0.03$ & --- & --- & --- \\
\hline \multicolumn{6}{|l|}{ Orden Carcharhiniformes } \\
\hline \multicolumn{6}{|l|}{ Familia Carcharhinidae } \\
\hline 6 Triaenodon obesus & --- & --- & --- & --- & --- \\
\hline \multicolumn{6}{|l|}{ Orden Mugiliformes } \\
\hline \multicolumn{6}{|l|}{ Familia Mugilidae } \\
\hline 7 Mugil curema & --- & --- & -- & --- & -- \\
\hline \multicolumn{6}{|l|}{ Orden Perciformes } \\
\hline \multicolumn{6}{|l|}{ Familia Acanthuridae } \\
\hline 8 Acanthurus nigricans & --- & --- & --- & --- & --- \\
\hline 9 Acanthurus triostegus & --- & --- & --- & --- & --- \\
\hline 10 Acanthurus xanthopterus & 0.03 & --- & --- & 0.08 & --- \\
\hline 11 Prionurus laticlavius & --- & 0.08 & --- & --- & --- \\
\hline 12 Prionurus punctatus & --- & --- & --- & --- & --- \\
\hline \multicolumn{6}{|l|}{ Familia Apogonidae } \\
\hline 13 Apogon dovii & --- & $0.20 \pm 0.16$ & 0.05 & --- & --- \\
\hline \multicolumn{6}{|l|}{ Familia Blenniidae } \\
\hline 14 Ophioblennius steindachneri & --- & --- & --- & --- & --- \\
\hline 15 Plagiotremus azaleus & --- & --- & --- & --- & --- \\
\hline 16 Caranx caballus & --- & --- & --- & --- & --- \\
\hline 17 Caranx melampygus & --- & --- & --- & --- & --- \\
\hline 18 Elagatis bipinnulata & -- & -- & --- & -- & --- \\
\hline 19 Gnathanodon speciosus & --- & --- & 0.03 & --- & --- \\
\hline \multicolumn{6}{|l|}{ Familia Chaetodontidae } \\
\hline 20 Chaetodon humeralis & --- & $0.06 \pm 0.05$ & $0.04 \pm 0.02$ & $0.11 \pm 0.12$ & $0.05 \pm 0.02$ \\
\hline 21 Johnrandallia nigrirostris & --- & $0.03 \pm 0.02$ & --- & $0.05 \pm 0$ & $0.09 \pm 0.09$ \\
\hline \multicolumn{6}{|l|}{ Familia Cirrhitidae } \\
\hline 22 Cirrhitichthys oxycephalus & --- & --- & --- & --- & --- \\
\hline 23 Cirrhitus rivulatus & --- & --- & --- & --- & --- \\
\hline \multicolumn{6}{|l|}{ Familia Ephippidae } \\
\hline 24 Chaetodipterus zonatus & --- & --- & --- & 0.75 & --- \\
\hline \multicolumn{6}{|l|}{ Familia Gobiidae } \\
\hline 25 Elacatinus punticulatus & --- & --- & --- & --- & $0.29 \pm 0.19$ \\
\hline \multicolumn{6}{|l|}{ Familia Haemulidae } \\
\hline 26 Anisotremus caesius & --- & $0.04 \pm 0.02$ & --- & $0.60 \pm 0.74$ & $0.03 \pm 0$ \\
\hline 27 Anisotremus interruptus & --- & $0.04 \pm 0.02$ & --- & --- & $0.14 \pm 0.16$ \\
\hline 28 Anisotremus taeniatus & --- & --- & --- & --- & $0.12 \pm 0.09$ \\
\hline 29 Haemulon flaviguttatum & --- & --- & --- & 5.00 & --- \\
\hline 30 Haemulon maculicauda & 0.15 & $1.63 \pm 3.16$ & --- & $0.39 \pm 0.22$ & $0.33 \pm 0.30$ \\
\hline 31 Haemulon scudderi & --- & -- & --- & --- & --- \\
\hline 32 Haemulon sexfasciatum & -- & -- & --- & -- & --- \\
\hline 33 Haemulon steindachneri & --- & --- & --- & --- & --- \\
\hline Familia Kyphosidae & & & & & \\
\hline 34 Kyphosus analogus & 0.03 & --- & --- & --- & --- \\
\hline 35 Kyphosus elegans & --- & --- & --- & --- & --- \\
\hline 36 Kyphosus spp. & --- & --- & --- & --- & --- \\
\hline 37 Sectator ocyurus & --- & --- & --- & --- & --- \\
\hline Familia Labridae & & & & & \\
\hline 38 Bodianus diplotaenia & --- & 0.05 & --- & 0.03 & 0.05 \\
\hline 39 Halichoeres chierchiae & --- & --- & --- & --- & --- \\
\hline
\end{tabular}


ANEXO 3 (Continuación)

\begin{tabular}{|c|c|c|c|c|c|}
\hline Especie & 23 & 24 & 25 & 26 & 27 \\
\hline 40 Halichoeres dispilus & $1.28 \pm 2.06$ & $1.06 \pm 0.57$ & $1.58 \pm 1.32$ & $0.54 \pm 0.66$ & $0.31 \pm 0.31$ \\
\hline 41 Halichoeres melanotis & --- & --- & --- & --- & --- \\
\hline 42 Halichoeres nicholsi & 0.03 & $0.04 \pm 0.01$ & --- & --- & 0.05 \\
\hline 43 Halichoeres notospilus & 0.03 & --- & --- & --- & --- \\
\hline 44 Novaculichthys taeniourus & --- & --- & --- & --- & --- \\
\hline 45 Thalassoma grammaticum & --- & --- & --- & --- & --- \\
\hline 46 Thalassoma lucasanum & $0.47 \pm 0.41$ & $0.33 \pm 0.21$ & $0.04 \pm 0.01$ & $0.34 \pm 0.25$ & $0.18 \pm 0.13$ \\
\hline \multicolumn{6}{|l|}{ Familia Labrisomidae } \\
\hline 47 Malacoctenus zonifer & --- & 0.15 & --- & --- & --- \\
\hline \multicolumn{6}{|l|}{ Familia Lutjanidae } \\
\hline 48 Hoplopagrus guentherii & --- & --- & --- & --- & --- \\
\hline 49 Lutjanus argentiventris & $0.10 \pm 0.04$ & $0.13 \pm 0.14$ & --- & $0.54 \pm 0.78$ & $0.18 \pm 0.24$ \\
\hline 50 Lutjanus guttatus & $1.68 \pm 2.87$ & --- & 0.10 & 0.50 & --- \\
\hline 51 Lutjanus inermis & --- & --- & --- & --- & --- \\
\hline 52 Lutjanus novemfasciatus & --- & $0.04 \pm 0.02$ & --- & $0.15 \pm 0.14$ & --- \\
\hline 53 Lutjanus viridis & --- & --- & --- & --- & --- \\
\hline \multicolumn{6}{|l|}{ Familia Mullidae } \\
\hline 54 Mulloidichthys dentatus & --- & --- & --- & --- & --- \\
\hline 55 Pseudupeneus grandisquamis & --- & --- & --- & --- & --- \\
\hline \multicolumn{6}{|l|}{ Familia Pomacanthidae } \\
\hline 56 Holacanthus passer & --- & --- & --- & --- & 0.05 \\
\hline 57 Pomacanthus zonipectus & --- & 0.03 & --- & $0.03 \pm 0.01$ & $0.03 \pm 0$ \\
\hline \multicolumn{6}{|l|}{ Familia Pomacentridae } \\
\hline 58 Abudefduf troschelii & $0.31 \pm 0.21$ & $0.75 \pm 0.50$ & --- & $0.84 \pm 0.87$ & $0.14 \pm 0.09$ \\
\hline 59 Chromis atrilobata & --- & $0.62 \pm 0.73$ & --- & --- & --- \\
\hline 60 Microspathodon dorsalis & --- & --- & --- & --- & --- \\
\hline 61 Stegastes acapulcoensis & $0.46 \pm 0.31$ & $0.16 \pm 0.08$ & 0.13 & $0.48 \pm 0.40$ & $0.52 \pm 0.27$ \\
\hline 62 Stegastes spp. & 0.03 & --- & --- & 0.30 & --- \\
\hline 63 Stegastes rectrifaenum & $0.08 \pm 0.04$ & $0.28 \pm 0.14$ & --- & $0.38 \pm 0.31$ & $0.39 \pm 0.04$ \\
\hline \multicolumn{6}{|l|}{ Familia Scaridae } \\
\hline 64 Scarus compressus & --- & --- & --- & --- & --- \\
\hline 65 Scarus ghobban & 0.08 & $0.09 \pm 0.07$ & --- & $0.73 \pm 0.89$ & $0.39 \pm 0.47$ \\
\hline 66 Scarus perrico & 0.03 & --- & --- & --- & --- \\
\hline 67 Scarus rubroviolaceus & --- & 1.00 & --- & --- & --- \\
\hline \multicolumn{6}{|l|}{ Familia Sciaenidae } \\
\hline 68 Odontoscion xanthops & --- & --- & --- & --- & --- \\
\hline \multicolumn{6}{|l|}{ Familia Serranidae } \\
\hline 69 Alphestes immaculatus & --- & --- & --- & --- & --- \\
\hline 70 Cephalopholis panamensis & $0.06 \pm 0.06$ & $0.03 \pm 0.01$ & --- & $0.05 \pm 0$ & $0.05 \pm 0.02$ \\
\hline 71 Dermatolepis dermatolepis & --- & --- & --- & --- & --- \\
\hline 72 Epinephelus labriformis & $0.03 \pm 0$ & --- & --- & 0.03 & 0.03 \\
\hline 73 Paranthias colonus & --- & $0.06 \pm 0.05$ & --- & --- & --- \\
\hline 74 Rypticus nigripinnis & --- & --- & 0.03 & --- & --- \\
\hline 75 Serranus psittacinus & $0.04 \pm 0.02$ & --- & $0.07 \pm 0.04$ & 0.05 & --- \\
\hline \multicolumn{6}{|l|}{ Familia Zanclidae } \\
\hline 76 Zanclus cornutus & --- & $0.03 \pm 0$ & --- & --- & --- \\
\hline \multicolumn{6}{|l|}{ Orden Rajiformes } \\
\hline \multicolumn{6}{|l|}{ Familia Dasyatidae } \\
\hline 77 Dasyatis longa & --- & 0.03 & --- & --- & --- \\
\hline \multicolumn{6}{|l|}{ Orden Scorpaeniformes } \\
\hline \multicolumn{6}{|l|}{ Familia Scorpaenidae } \\
\hline 78 Scorpaena mystes & 0.03 & --- & --- & --- & --- \\
\hline 79 Scorpaena spp. & --- & --- & --- & --- & --- \\
\hline \multicolumn{6}{|l|}{ Orden Syngnathiformes } \\
\hline \multicolumn{6}{|l|}{ Familia Aulostomidae } \\
\hline 80 Aulostomus chinensis & --- & --- & --- & --- & --- \\
\hline \multicolumn{6}{|l|}{ Familia Fistulariidae } \\
\hline 81 Fistularia commersonii & --- & --- & --- & --- & --- \\
\hline
\end{tabular}


ANEXO 3 (Continuación)

\section{Especie}

Orden Tetraodontiformes

Familia Balistidae

82 Balistes polylepis

83 Melichthys niger

84 Pseudobalistes naufragium

85 Sufflamen verres

Familia Diodontidae

86 Diodon hystrix

Familia Ostraciidae

87 Ostracion meleagris

Familia Tetraodontidae

88 Arothron hispidus

89 Arothron meleagris

90 Canthigaster punctatissima

$\mathrm{S}$

$H^{\prime}(\log 10)$

$\Delta^{*}$
23

24

25

26

$\begin{array}{ccccc}--- & 0.03 & --- & 0.04 \pm 0.02 & 0.06 \pm 0.05 \\ --- & --- & --- & --- & --- \\ --- & -- & --- & 0.04 \pm 0.02 & --- \\ 0.04 \pm 0.02 & 0.14 \pm 0.16 & --- & 0.03 & --\end{array}$

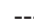

$-$

$--$

0.03

23

0.8477

50.92

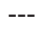

$---$

$-$

$\cdots$

$--$

29

1.058

69.43
$--$

$---$

$\cdots$

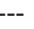

$--$

9

0.6364

49.89

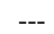

$---$

0.03

$---$

$---$

27

1.084

51.45
0.03

22

1.008 
